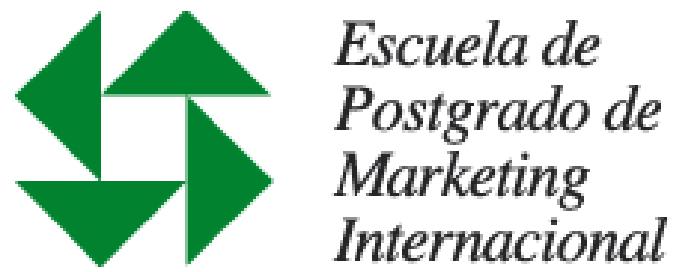

\title{
Concepción de marketing internacional para la importación de membranas asfálticas de origen argentino para edificaciones en el Estado Plurinacional de Bolivia
}
Trabajo Científico-Técnico aplicativo libre para la obtención del grado de Magister en Marketing Internacional de la Escuela de Posgrado de Marketing Internacional Facultad de Ciencias Económicas - Universidad Nacional de La Plata - Argentina

Profesor Director de Tesis:

Presentado por:

Dr. Ing. José A. París

Mayra A. Fuentes

Calle: Juncal №3186

(Buenos Aires)

Fecha de Entrega: Marzo 2015 



\section{Índice}

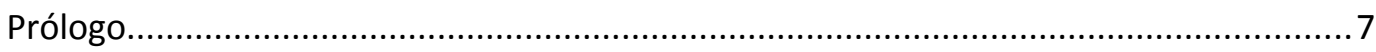

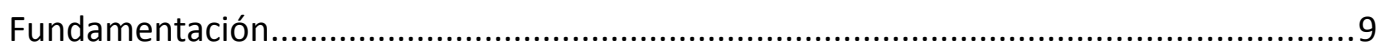

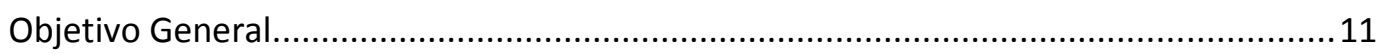

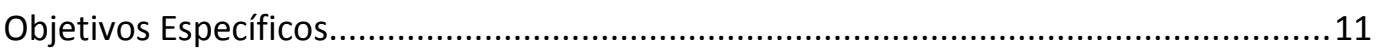

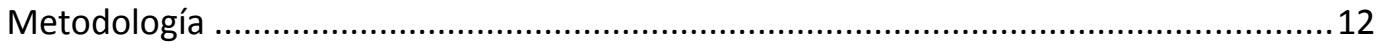

Capítulo 1. Identificación de la necesidad de importación de insumos para el sector de la construcción en el Estado Plurinacional de Bolivia- Etapa de diagnóstico......................13

1.1 Oportunidad comercial entre el Estado Plurinacional de Bolivia - Argentina............13

1.2 Características del mercado de impermeabilizantes en el sector de la construcción en el Estado Plurinacional de Bolivia..........................................................................16

1.2.1 Principales materiales utilizados para el techado de edificaciones........................16

1.2.2 Principales empresas locales importadoras de membranas asfálticas..................17

1.2.3 Origen y marca de las principales importaciones de membranas asfálticas...18

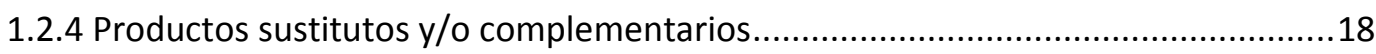

Capítulo 2. Estrategia general para la composición de la empresa comercializadora de membranas asfálticas en el Estado Plurinacional de Bolivia- Plan Estratégico.................20

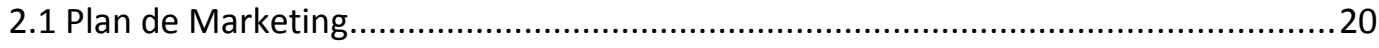

2.1.1 Descripción y filosofía del plan de marketing .....................................................20

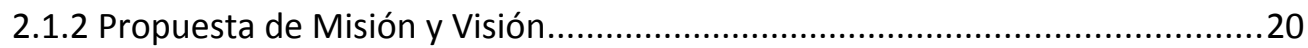

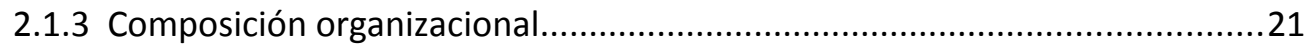

2.1.4 Concepción financiera a largo plazo..........................................................22

2.2 Análisis político, económico, social y tecnológico (PEST) .........................................22

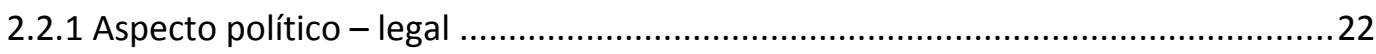

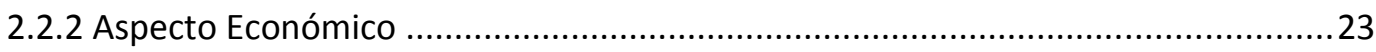

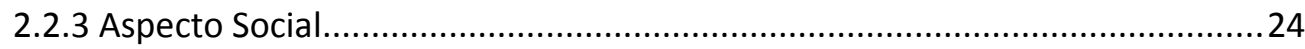

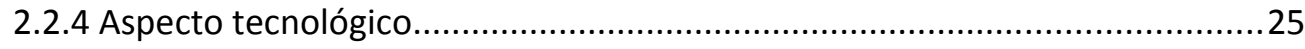

2.3 Análisis de las Fortalezas, Oportunidades, Debilidades y Amenazas (FODA).............25

2.4 Análisis de las aspiraciones, restricciones y coordinación de las operaciones del

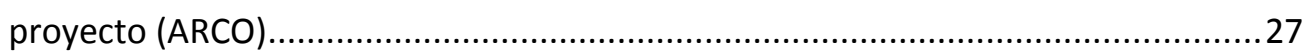

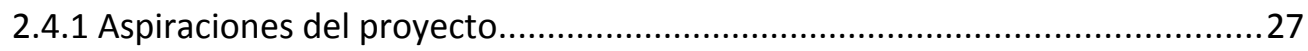

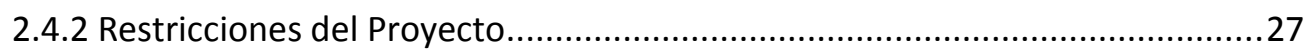

2.4.3 Capacidades de la organización..................................................................32

Universidad Nacional de La Plata - Escuela de Postgrado de Marketing Internacional 


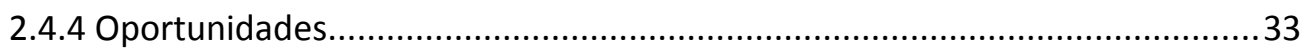

2.5 Definición estratégica general del negocio...............................................................33

Capítulo 3. Análisis del producto desde una perspectiva del marketing en Argentina...35

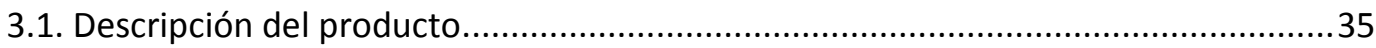

3.1.1 Atributos del producto intrínsecos, externos................................................35

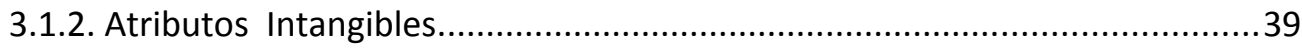

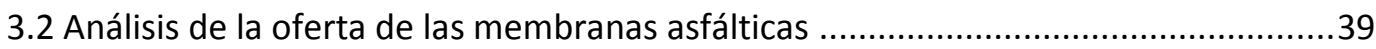

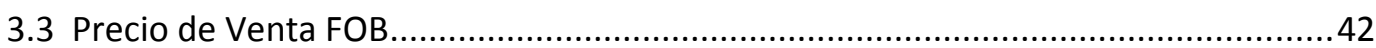

3.3.1 Incoterms (International Comercial Terms) ................................................42

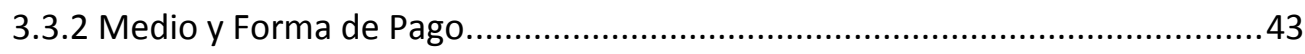

Capítulo 4. Estrategia de marketing internacional para la importación de membranas asfálticas de origen argentino en el Estado Plurinacional de Bolivia.............................43

4.1 Aspectos relevantes para la importación ...............................................................43

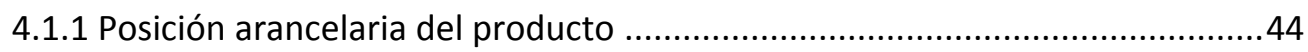

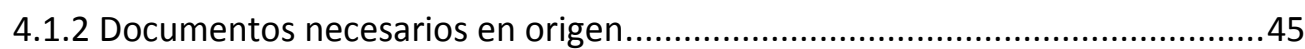

4.2 Acuerdos comerciales entre el Estado Plurinacional de Bolivia y Argentina.............45

4.3 Aspectos relevantes para la importación en destino.................................................45

4.3.2 Barreras no arancelarias al ingreso del producto.........................................46

4.4 Determinación de la logística y transporte................................................................47

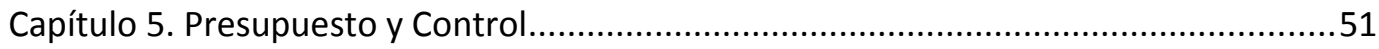

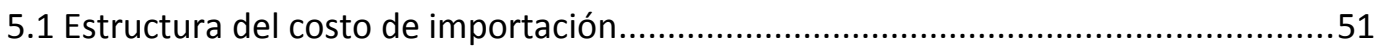

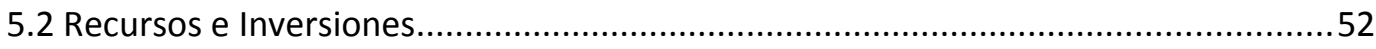

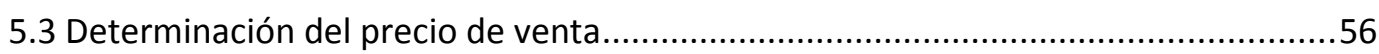

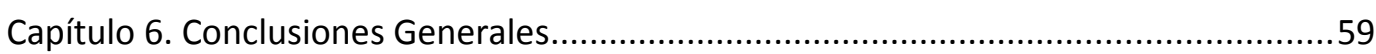

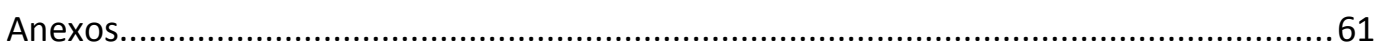

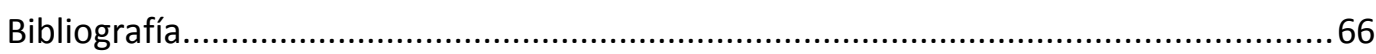

Índice de llustraciones

\section{Índice de tablas}


A mis padres, que son el pilar fundamental de mi vida.

\section{Agradecimientos}

Este trabajo de tesis realizado en la Universidad Nacional de La Plata- Escuela de Postgrado de Marketing Internacional es un esfuerzo en el cual directa o indirectamente participaron varias personas opinando, corrigiendo, teniéndome paciencia, dándome ánimo en momentos de complejidad o felicidad, por tal motivo en este apartado deseo dar las gracias.

En primer lugar, a mi director de tesis Dr. José Antonio París, por su valiosa dirección y apoyo para seguir el desarrollo de esta tesis y llegar a la conclusión de la misma.

Un especial agradecimiento a la Magister Liesel Bischoff, secretaria académica, por la paciencia y dedicación que nos otorgó a los maestrandos, particularmente por haberme orientando constantemente en todo el desarrollo de la maestría, como también en la realización de la tesis. 
A mi familia y amigos por apoyarme incondicionalmente, por brindarme su amor traspasando fronteras, sobre todo por creer y confiar en mí.

\section{Prólogo}

"A lo largo del tiempo, el hombre ha utilizado para refugiarse desde, la sombra de los árboles y las cavernas naturales, pasando por los toldos y chozas, hasta llegar a las viviendas actuales." ${ }^{1}$

El techo es la parte más esencial de una edificación, porque gracias a éste se da el nombre de edificio o casa; sin embargo es el elemento que más cuesta realizar y mantener, debido a que se encuentra expuesto constantemente a las inclemencias naturales y también porque es la responsable trascendental del confort interior.

Uno de los principales agentes climáticos que agreden a los techos y azoteas es la humedad, ésta puede ser generada por el agua de lluvia o la acumulación de la misma, provocando a corto plazo una serie de manchas en el interior de la edificación, a posteriori un desprendimiento de pintura y/o reblandecimientos de paredes, techos llegando finalmente a un colapso de la infraestructura.

Para evitar daños de este tipo ocasionados por la humedad existen varias sustancias químicas especializadas, entre ellas se encuentran los impermeabilizantes.

1 Dimatre, Norberto(Septiembre del 1998) La vivienda en tiempos remotos hasta nuestros días en el mediterráneo, Hábitat, Conservación \& Reciclaje, ed Buenos Aires 
Entre uno de los tipos de impermeabilizantes efectivos tenemos a las membranas asfálticas. Para el Instituto de Tecnología Industrial (INTI) ${ }^{2}$ las membranas asfálticas están compuestas en general por láminas asfálticas con una o varias armaduras con una recubierta asfáltica (bitúmenes obtenidos como residuo de la destilación del petróleo) y con un material antiadherente como terminación.

Existen tres tipos básicos de membranas asfálticas, diferenciadas por el tipo de recubrimiento ${ }^{3}$ :

- Membranas normales sin aluminio (para uso bajo carpeta, no expuestas)

- Membranas con revestimiento de aluminio no crack (no transitables)

- Membranas con revestimiento de geotextil (transitables)

En este proyecto nos enfocaremos en las membranas asfálticas con revestimiento geotextil.

La membrana asfáltica revestida con tejido de poliéster termoconformado (geotextil) es un impermeabilizante que puede resistir todo tipo de agresiones mecánicas o climáticas, es idóneo para utilizarlo en terrazas transitables, canales de irrigación, sótanos, cimientos, jardines y canteros.
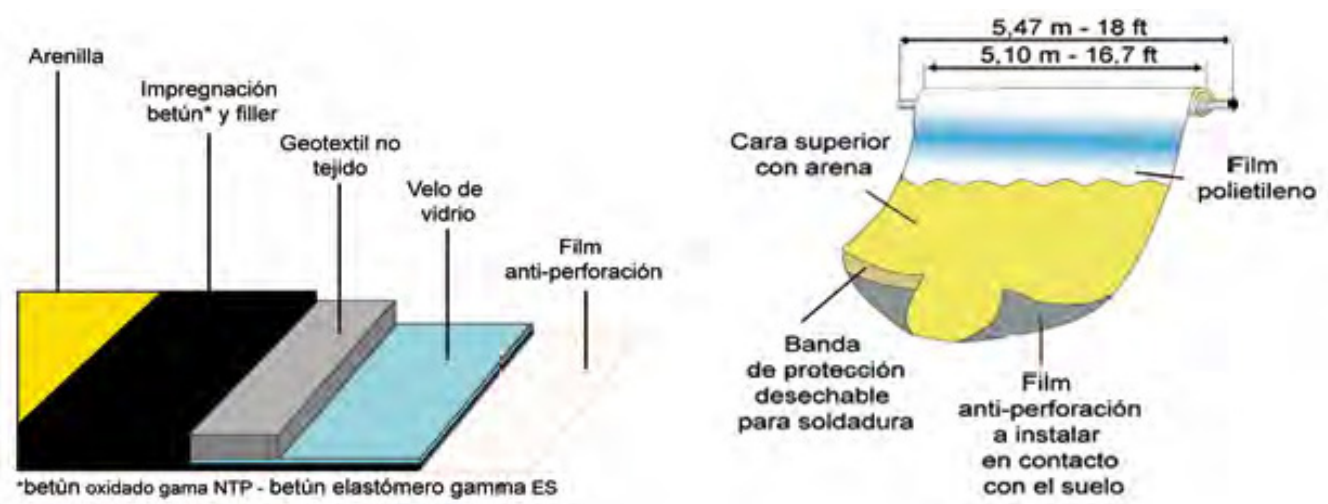

llustración 1.Composición de las membranas asfálticas

La aplicación de la membrana pre elaborada con recubrimiento textil debe realizarse por una persona idónea, ya que esta colocación consta de dos pasos esenciales: imprimación y aplicación de la membrana.

2 Instituto de Tecnología Industrial (INTI) "Reciclado de Membranas Asfálticas”, 2012. recuperado (10 octubre 2014)

3 Membranas Avellaneda, recuperado ( 20 de octubre del 2014) http://www.membranasavellaneda.com.ar/ 
Este tipo de impermeabilizante a diferencia de los tradicionales como las pinturas, es más efectivo y duradero, razón por la cual es muy solicitado en las edificaciones.

Actualmente el sector de la construcción de Bolivia está atravesando un crecimiento importante. Para la Cámara Boliviana de la Construcción $(\mathrm{CABOCO})^{4}$, "El crecimiento del sector cerró con 7,6 \% en 2013 y en 2014 se prevé un incremento hasta un $9 \%$.

Bolivia $^{5}$ aprobó el primer decreto supremo de la nueva ley de Servicios financieros, la cual fija tasas máximas que oscilan entre $5,5 \%$ y $6,5 \%$ para los créditos de vivienda.

Según un comunicado de prensa emitido por el Fondo Monetario Internacional (FMI) ${ }^{6}$ Bolivia presenta un sólido crecimiento del Producto Interno Bruto (PIB), donde también analizaron que hasta finales del 2014 se tendrá una disminución de la inflación.

Considerando la importancia que tiene el sector de la construcción en la economía boliviana y asumiendo el crecimiento proyectado del mismo por las instituciones privadas y públicas, este estudio plantea establecer aspectos relevantes del marketing internacional para la importación de membranas asfálticas de origen argentino para la impermeabilización de edificaciones en territorio boliviano.

\section{Fundamentación}

La actividad del sector de la construcción es clave para la vida económica de un país ya que moviliza a otras múltiples industrias productoras de insumos, de igual manera a los sectores de comercio y transporte; generando diversas fuentes laborales.

En Bolivia el sector de la construcción tiene un crecimiento importante, esto tiene una incidencia en la comercialización de insumos o materiales necesarios.

4 Cámara Nacional de la Construcción de Bolivia, recuperado (17 de junio del 2014) http://www.caboco.org.bo/ 5 Gaceta Oficial del Estado Plurinacional de Bolivia, recuperado (18 de junio del 2014) http://www.gacetaoficialdebolivia.gob.bo/

6 Fondo Monetario de Inversión, recuperado (17 de junio del 2014) http://www.imf.org/external/spanish/np/tr/2014/tr021014s.htm 
Según la Comisión Económica para América Latina y El Caribe (CEPAL) ${ }^{7}$ en la gestión 2013, Bolivia ocupó el primer lugar de los países de la región que exportan materias primas, principalmente hidrocarburos y minería, pero contradictoriamente ocupa la última posición entre quienes venden productos industriales manufacturados.

Con lo que podemos decir que existen varios insumos para la construcción que necesariamente deben ser importados, para poder satisfacer la demanda actual.

En la tabla1 podemos apreciar que del total de importaciones que genera Bolivia un $29 \%$ son destinadas a bienes intermedios, los cuales provienen de países como Brasil, Argentina, Estados Unidos y Perú.

Tabla 1. Importaciones realizadas por Bolivia según categoría económica

\begin{tabular}{|c|c|c|}
\hline $\begin{array}{c}\text { Importaciones realizadas por Bolivia } \\
\text { según categoría económica (Primer } \\
\text { semestre 2014) }\end{array}$ & $\begin{array}{l}\text { Valor } \\
\text { (Expresado en } \\
\text { US\$) }\end{array}$ & $\begin{array}{c}\text { Valor } \\
\text { Porcentual (\%) }\end{array}$ \\
\hline Alimentos y Bebidas & 358.045 .666 & 7 \\
\hline Suministros Industriales & 1.395 .870 .774 & 29 \\
\hline Combustibles y Lubricantes & 523.738 .941 & 11 \\
\hline $\begin{array}{c}\text { Bienes de Capital sus piezas y } \\
\text { accesorios }\end{array}$ & 1.251.111.344 & 26 \\
\hline $\begin{array}{c}\text { Equipos de Transporte sus piezas y } \\
\text { accesorios }\end{array}$ & 695.253 .181 & 14 \\
\hline $\begin{array}{c}\text { Bienes de consumo no especificados } \\
\text { en otra partida }\end{array}$ & 509.636 .490 & 10 \\
\hline $\begin{array}{c}\text { Artículos de Consumo no Especificados } \\
\text { en otra partida }\end{array}$ & 2.383 .742 & 3 \\
\hline
\end{tabular}

Fuente: Instituto Nacional de Estadística (INE) e Instituto Boliviano de Comercio Exterior (IBCE)- Elaboración Propia

7 Comisión Económica para América Latina y El Caribe (CEPAL) recuperado ( 8 de julio del 2014)

http://www.cepal.org/publicaciones/xml/6/51946/AnuarioEstadistico2013.pdf 
La Asociación Latinoamericana de Integración (ALADI) ${ }^{8}$ afirma que Argentina con un 10,90\% ocupa el cuarto lugar en orden de importancia para Bolivia en lo que se refiere a importaciones

En una nota de prensa emitida en mayo del 2014 por la Fundación ExportAr ${ }^{9}$ de las ventas que realiza Argentina a Bolivia el 60\% corresponden a manufacturas de origen industrial, repuestos para motores, aparatos y partes eléctricas, artículos de grifería y órganos similares para tuberías, calderas entre otros.

En un informe emitido en 2012 por el Instituto Nacional de Tecnología Industrial (INTI) ${ }^{10}$ del total de producción de asfalto argentino el $18 \%$ es destinado a la fabricación de membranas asfálticas las cuales son utilizadas como impermeabilizantes en edificaciones; en el mismo informe señalaron que la

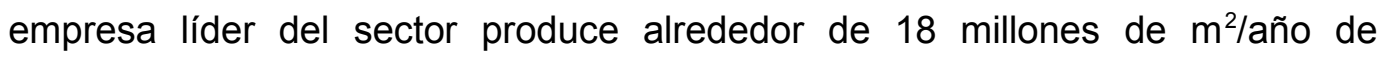
membranas asfálticas.

Con el afán de satisfacer las necesidades del sector de la construcción boliviana, se ve una oportunidad de negocio internacional a iniciar pero, para esto es necesario determinar claramente los conceptos de marketing internacional aplicables.

\section{Objetivo General}

Determinar los lineamientos idóneos en un marco genérico, para la importación de membranas asfálticas bajo un análisis de las herramientas del marketing internacional.

\section{Objetivos Específicos}

- Identificar la estrategia de marketing internacional adecuado para planificar la importación.

8 Asociación Latinoamericana de Integración (ALADI), recuperado (10 de julio del 2014)

http://consultawebv2.aladi.org/sicoexV2/jsf/comercio_exterior_principales_socios_resultado.seam?cid=1080

9 Fundación ExportAr recuperado, (10 de agosto del 2014)

http://www.exportar.org.ar/web2013/accion.php?st=fer\&ndoc=999

10Instituto de Tecnología Industrial (INTI), recuperado (31 de agosto del 2014)

http://www.inti.gob.ar/jornadasgirsu2012/pdf/disertaciones/Panel_InvestigacionDesarrolloTecnologiasRSU/Me mbranas_Asfalticas_Alberto_Gauna.pdf_ 
- Establecer los aspectos relevantes para importación de las membranas asfálticas en el mercado a incursionar.

\section{Metodología}

El esquema de investigación es exploratorio, a los efectos de detectar los aspectos del marketing internacional en general, aplicados a un caso puntual de comercialización internacional de membranas asfálticas de origen argentino en Bolivia. Para esto se utilizarán las siguientes fuentes:

> Fuentes Primarias, realizando entrevistas en profundidad con expertos del área de marketing, comercio exterior y la construcción tanto en origen como en destino.

> Fuentes Secundarias, estudio bibliográfico actualizado sobre el producto y segmento a importar.

El ordenamiento de datos será cualitativo por la correlación de variables que utilizaremos para tomar decisiones. 


\section{Capítulo 1. Identificación de la necesidad de importación de insumos para el sector de la construcción en el Estado Plurinacional de Bolivia- Etapa de diagnóstico}

\subsection{Oportunidad comercial entre el Estado Plurinacional de Bolivia - Argentina}

Es primordial explicar en el presente proyecto la razón por la cual se determina la operación de comercio internacional entre ambos países, pero antes de eso se expondrán los motivos por el que Bolivia es atractiva para la comercialización de membranas asfáltica para impermeabilización de techos.

En los últimos años en Bolivia se registró un crecimiento importante en el sector de la construcción, este se puede evidenciar con datos generados por indicadores del sector como el producto interno bruto, los permisos de construcción, el consumo de cemento y el financiamiento de la construcción entre otros.

$>\quad$ Producto Interno Bruto: La variación del PIB de la construcción siempre ha ido ligada al PIB nacional, ya que la construcción es el termómetro de la economía. Vargas, M. (2014, junio 3). Administrador General de la Cámara de Construcción de Cochabamba. Entrevista Personal: "De acuerdo con el Índice Global de Actividad Económica (IGAE) difundido por el ministerio de economía y finanzas del estado, hasta marzo de 2014 la economía boliviana creció 6,49\% gracias al impulso de la construcción (10,79\%), industria manufacturera $(6,45 \%)$, comercio $(4,25 \%)$ y minería $(3,03 \%)$, entre otros sectores". ${ }^{11}$

El sector de la construcción representa el 10\% del Producto interno Bruto del país; es decir alrededor de \$us 3.000 millones y su crecimiento anual estimado es de $10 \% .^{12}$

11 Instituto Nacional de Estadística de Bolivia (INE), recuperado el (23 de noviembre del 2014) http://www.ine.gob.bo/indice/general.aspx?codigo $=40221$ 
> Permisos de construcción: Para el Observatorio Urbano de Santa Cruz (OBU) el $82 \%$ de los permisos de construcción se encuentran en el eje troncal del país, es decir que en las ciudades de Santa Cruz, Cochabamba y La Paz se registraron $2.806 .818 \mathrm{~m}^{2}$ construidos; de los cuales el $52 \%$ corresponde a Santa Cruz.

La mayoría de las obras que se están generando son destinadas a servicios, comercio, hotelería y recreación al igual que las casas individuales y/o edificios (departamentos), donde también se habilita un espacio al comercio.

> Tabla 2. Permisos de construcción aprobados por ciudades importantes de Bolivia, (2010-2012) (En metros cuadrados)

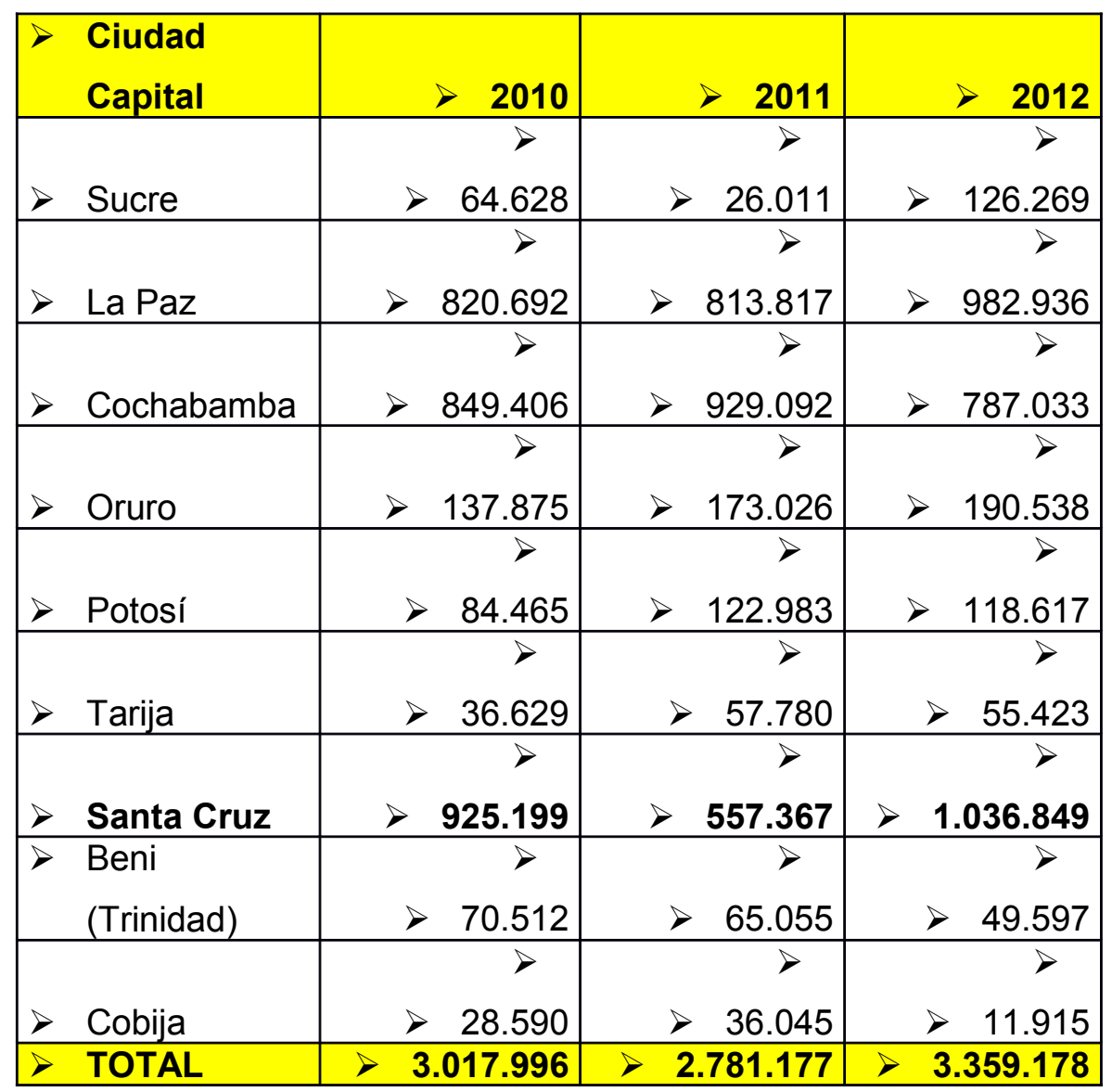

Fuente: Instituto de Estadística (INE), Elaboración propia.

Consumo de cemento: En este último año se llegó a consumir alrededor de 3 millones de toneladas métricas; este consumo va ligado al incremento de las obras de construcción en el país.

Financiamiento de la construcción: El estado es consciente del impacto que tuvo el sector de la construcción en el incremento del PIB nacional en estos últimos meses, por tal motivo mediante un proyecto de inversión planea que el sector crezca un $14 \%$, por otro lado, también se aprobó la ley de 
Servicios Financieros ${ }^{13}$, con la que se fomenta el acceso a créditos con tasas de interés fijas con el único objetivo de reactivar el aparato productivo.

Tabla 3. Financiamiento concedido por el sistema financiero a la construcción (2010-2012) Expresado en millones de bolivianos

\begin{tabular}{|l|l|l|l|}
\hline$>$ Financiamiento & $>\mathbf{2 0 1 0}$ & $>$ 2011 & $>$ 2012(*) \\
\hline$>$ Bancario & $>4.679,00$ & $>5.636,29$ & $>6.045,49$ \\
\hline$>$ No Bancario & $>2.653,70$ & $>2.716,65$ & $>2.827,56$ \\
\hline$>$ Total & $>7.332,70$ & $>8.352,94$ & $>8.873,05$ \\
\hline
\end{tabular}

$>$ Fuente: Banco Central de Bolivia - Elaboración Cámara de la Construcción de Cochabamba. www.cadecocbba.com

$>$ Por otro lado se ve en la tabla 4 que existe un gran porcentaje de variación en cuanto al incremento de empresas dedicadas al rubro de la construcción; Santa Cruz de la Sierra ocupa el primer lugar con un $28,9 \%$.

$>$ Tabla 4. Empresas dedicadas a la actividad de construcción según departamento (2005-2012)

\begin{tabular}{|c|c|c|c|c|c|c|c|c|c|c|}
\hline Departamento & 2005 & 2006 & 2007 & 2008 & 2009 & 2010 & 2011 & 2012 & Part. Porc. 2012 & Var porc 2012-2011 \\
\hline La Paz & 985 & 1.233 & 1.385 & 1.542 & 2.001 & 2.270 & 2.849 & 3.501 & $34,8 \%$ & $22,9 \%$ \\
\hline Santa Cruz & 491 & 583 & 695 & 733 & 849 & 980 & 1.137 & 1.466 & $14,6 \%$ & $28,9 \%$ \\
\hline Cochabamba & 319 & 439 & 538 & 598 & 740 & 902 & 1.166 & 1.443 & $14,3 \%$ & $23,8 \%$ \\
\hline Oruro & 207 & 316 & 407 & 458 & 553 & 684 & 834 & 890 & $8,8 \%$ & $6,7 \%$ \\
\hline Tarija & 652 & 737 & 676 & 597 & 515 & 536 & 653 & 747 & $7,4 \%$ & $14,4 \%$ \\
\hline Potosí & 193 & 292 & 335 & 364 & 495 & 593 & 649 & 744 & $7,4 \%$ & $14,6 \%$ \\
\hline Chuquisaca & 278 & 333 & 302 & 299 & 427 & 599 & 682 & 755 & $7,5 \%$ & $10,7 \%$ \\
\hline Beni & 51 & 121 & 217 & 212 & 216 & 290 & 347 & 385 & $3,8 \%$ & $11,0 \%$ \\
\hline Pando & 8 & 33 & 44 & 44 & 54 & 96 & 118 & 129 & $1,3 \%$ & $9,3 \%$ \\
\hline Total & 3.184 & 4.087 & 4.599 & 4.847 & 5.850 & 6.950 & 8.435 & 10.060 & $100,0 \%$ & $19,3 \%$ \\
\hline
\end{tabular}

Fuente: FUNDEMPRESA www.fundempresa.com.org

$>$ En cuanto a los productos de origen argentino, presentan una gran acogida en Bolivia, debido a la calidad que ofrecen, por otro lado todos los acuerdos bilaterales existentes entre ambos países son un plus al momento de realizar un intercambio comercial.

$>$ En la siguiente tabla difundida por el Ministerio de Relaciones ExterioresViceministerio de Comercio Exterior e Integración (VCEI) refleja los principales países desde los que Bolivia registró un incremento en sus importaciones, en el cual Argentina ocupa el cuarto lugar con un 37\% de incremento en relación al año 2013.

$>$ Tabla 5. Principales países desde los que Bolivia registró un incremento en sus importaciones (Febrero 2013 - 2014, expresado en millones de dólares)

\begin{tabular}{|l|l|l|l|}
\hline$>$ Descripción & $>$ 2013 & $>$ 2014 & $>$ DIF. 2014- 2013 \\
\hline$>$ China & $>173,2$ & $>237,6$ & $>64,4$ \\
\hline
\end{tabular}

13 Ley N³93” Ley de Servicios Financieros recuperado ( 20 de noviembre de 2014) https://www.bcb.gob.bo/webdocs/sipav/Leyes/Ley393.pdf 


\begin{tabular}{|l|r|r|r|}
\hline $\begin{array}{l}\text { Estados } \\
\text { Unidos }\end{array}$ & $>155$ & $>208,8$ & $>53,7$ \\
\hline$>$ Singapur & $>4,2$ & $>57$ & $>52,8$ \\
\hline$>$ Argentina & $>143,6$ & $>181,5$ & $>37,9$ \\
\hline$>$ Italia & $>17,1$ & $>49$ & $>32$ \\
\hline$>$ España & $>15,2$ & $>45,8$ & $>30,6$ \\
\hline$>$ Austria & $>2,5$ & $>29,5$ & $>26,9$ \\
\hline$>$ Perú & $>87,3$ & $>102,6$ & $>15,4$ \\
\hline$>$ Japón & $>67$ & $>82,1$ & $>15$ \\
\hline
\end{tabular}

Fuente: Elaborado por Viceministerio de comercio exterior e integración (VCEI) en base a datos del Instituto Nacional de Estadística (INE)

\subsection{Características del mercado de impermeabilizantes en el sector de la construcción en el Estado Plurinacional de Bolivia.}

- 1.2.1 Principales materiales utilizados para el techado de edificaciones

$>\quad$ En el último censo realizado por el Instituto de Nacional de Estadística (INE) se determinó que los principales insumos utilizados para el techado de una edificación tanto en el área urbana como rural en Bolivia son las chapas metálicas y teja (cemento, arcilla, fibrocemento), tal como se evidencia en los siguientes gráficos.

Ilustración 2. Materiales de construcción utilizados en techos (área urbana) 
$>$ Ilustración 3. Materiales de construcción utilizados en techos (área rural)

Fuente: Adaptado del Instituto Nacional de Estadística

\section{-1.2.2 Principales empresas locales importadoras de membranas asfálticas $^{14}$}

$>\quad$ Según investigación de campo en el lugar y consultando las diferentes cámaras de construcción de las principales ciudades de Bolivia, se determinó que las empresas dedicadas a la importación del producto se encuentran ubicadas en el eje troncal del país es decir La Paz, Cochabamba y Santa Cruz.

\section{$>$ La Paz}

$>\quad$ Importadora Antártida

$>\quad$ Sika Bolivia

Honnen Ltda.

Impermeabilizaciones Húmerez

\section{Santa Cruz}

14 Cámara de la Construcción Cochabamba (CADECO)

http://www.cadecocbba.com/controladores/index.php , Cámara de la Construcción Santa Cruz de la Sierra (CADECOCRUZ) http://www.cadecocruz.org.bo/ , Cámara de la Construcción de La Paz (CADECO - LA PAZ) http://www.cadecolp.com/ recuperado (20 noviembre 2014) 
Andrés Sossa Vaca

Coper Lux SRL

El Tiluchi Carandiru

Impersur

Industria Química Linox

Makose

Roka Ltda.

$>$ Cochabamba

Isomat Srl.

- 1.2.3 Origen y marca de las principales importaciones de membranas asfálticas

La gran mayoría de las membranas asfálticas que se comercializan en Bolivia son de origen argentino a continuación se exponen las marcas.

$>$ Tabla 6. Membranas comercializadas en Bolivia según marca y procedencia

\begin{tabular}{|l|l|l|}
\hline$>$ Marca & $>$ Procedencia & $>$ Comercializadora \\
\hline$>$ Megaflex & $>$ Argentina & $>$ Impersur Srl. \\
\hline$>$ Sika & $>$ Argentina & $>$ Sika (Bolivia) \\
\hline$>$ Chema & $>$ Perú & $>$ Isomat Srl. \\
\hline$>$ Ormiflex & $>$ Argentina & $>$ Honnen Ltda. \\
\hline$>$ Corpelux & $>$ Bérgamo-Italia & $>$ Coperlux Srl. \\
\hline$>$ Protex & $>$ Argentina & $>$ Protex Srl. \\
\hline$>$ Emapi & $>$ Argentina & $>$ Synergy Group \\
\hline
\end{tabular}

$>\quad$ Fuente: Adaptación de la Cámara de la Construcción de Santa Cruz, Cámara de la Construcción de Cochabamba, Cámara de la Construcción de La Paz (CADECO- LA PAZ)

$>\quad$ Después de haber realizado una cotización del producto con la empresa Honnen Ltda, se determinó que el precio ofertado por cada rollo de membrana asfáltica en la ciudad de Santa Cruz - Bolivia es de \$us 130. (Ver anexo 1). 
Existe una amplia gama de productos para la impermeabilización de techos, los cuales también son comercializados en territorio boliviano; uno de los más utilizados y básico son las pinturas acrílicas.

$>\quad$ Realizando un seguimiento del mercado boliviano existen dos empresas nacionales muy bien posicionadas dedicadas a la fabricación y comercialización de pinturas, Monopol Ltda. ${ }^{15}$ y American Chemical ${ }^{16}$, ambas con una presencia mayor a los 20 años, por otro lado también existen pinturas acrílicas de industria argentina, brasilera, peruana y estadunidense.

$>\quad$ Otros impermeabilizantes muy requeridos por el sector de la construcción son las membranas líquidas de poliuretano, neo impermeabilizantes, láminas liquidas que de igual manera son comercializadas con gran acogida por el mercado, lo cual en su mayoría son de industria argentina.

$>\quad$ Los impermeabilizantes mencionados anteriormente, si bien son ideales para proteger los techos de las edificaciones, no son aplicables en todas las construcciones, ya sea por la durabilidad o porque presentan distintas características para varios tipos de construcciones.

\subsubsection{Canales de comercialización de la competencia en Bolivia ${ }^{17}$}

Todas las marcas de membranas asfálticas para la impermeabilización de techos que se puede encontrar en Bolivia no son de origen importado, por lo cual el método de entrada al país se da de manera directa, es decir tienen oficinas propias en el país; y la segunda por medio de representantes comerciales.

La empresa que tiene presencia en Bolivia con oficinas propias es Sika Argentina S.A.I.C, esta tiene una amplia distribución en el eje troncal del país.

15 Pinturas Monopol recuperado (20 de noviembre del 2014) http://www.pinturasmonopol.com/

16 American Chemical recuperado (20 de noviembre del 2014)

http://www.americanchemical.com.bo/

17 Sika Bolivia S.A recuperado (20 de noviembre del 2014)

http://bol.sika.com/es/solutions products.html

Honnen Ltda. Recuperado (20 de noviembre del 2014) http://www.honnen.com.bo/subopcion.php? $\underline{D B}=$ homepage\&nroopcion=3\&nrosubop=17\&titulo Isomat Srl recuperado el 20 de noviembre del 2014. http://www.bo.all.biz/isomat-srl-e2991\#.VPSlevmG9LU 
$>$ Capítulo 2. Estrategia general para la composición de la empresa comercializadora de membranas asfálticas en el Estado Plurinacional de Bolivia- Plan Estratégico

$>$ En el presente capitulo identificaremos cual será las estrategia a seguir para poder realizar las importación de la mercadería.

\section{○ 2.1 Plan de Marketing}

$>\quad$ La planificación estratégica internacional de este proyecto requiere del análisis de varios factores del entorno o del contexto en el cual se desenvolverá en Bolivia, las oportunidades y dificultades que se pueden presentar al momento de incursionar el mismo. Para esto primero debemos enfocarnos en el cómo estará estructurada nuestra futura empresa, qué es lo que buscamos ofrecer y mediante qué medios lograremos lo propuesto.

\section{○ 2.1.1 Descripción y filosofía del plan de marketing}

$>$ Este proyecto se desarrolla con la finalidad de consolidar operaciones de importación y distribución de membranas asfálticas de origen argentino en mercado boliviano, basándonos en un factor clave de éxito, el cual será generar una completa red de proveedores que proporcionen un producto de excelente calidad.

> En cuanto a la cadena de comercialización, se puede decir que la importadora trabajará con distribuidores y mayoristas especializados en abastecer insumos de construcción en el eje troncal del país, de igual manera se pretende mantener contacto con algunos detallistas, que tengan presencia en provincias.

\section{- 2.1.2 Propuesta de Misión y Visión}

\section{Misión}

Ser una empresa importadora joven e innovadora, que distribuirá membranas asfálticas de industria argentina, con parámetros de calidad, precios 
> competitivos e inmejorables, satisfaciendo la necesidad del mercado demandante con un servicio de calidad.

\section{Visión}

$>$ En un plazo de 5 años pretendemos ser una empresa importadora reconocida en Bolivia por brindar productos de calidad, a un precio competitivo y al mismo tiempo por estar en la búsqueda constante de ampliar nuestra cartera de productos siguiendo las tendencias que marcan al sector de la construcción.

\section{- 2.1.3 Composición organizacional}

Se planea que la empresa adopte la forma jurídica de una sociedad de responsabilidad limitada (SRL); todos los trámites y requisitos necesarios para la apertura de la empresa estarán a cargo de asesores externos que los contrataremos en Bolivia.

$>$ El equipo de trabajo estará compuesto por seis (6) personas que se ocuparan de las siguientes áreas de la empresa.

$\checkmark$ Encargado Administrativo y contable: Se ocupara de todo el manejo administrativo y contable de la empresa, todo lo referido a cobros y pagos de proveedores, manejo de cuentas corrientes entre otras funciones

$\checkmark \quad$ Adquisición y Logística: Estará encargado de realizar los contactos con los proveedores en Argentina y de hacer todo el seguimiento del despacho de la mercadería hasta que llegue a destino.

$\checkmark \quad$ Marketing y ventas: El área estará compuesta por dos personas que tendrán la función de generar planes de ventas, estar en contacto continuamente con los clientes antes, durante y después de la venta de nuestro producto.

$\checkmark$ Almacén: Existirá una persona encargada de manejar el área del almacén, contabilizar el ingreso como egreso de la mercadería.

$\checkmark$ También contaremos con una persona dedicada a cuidar las instalaciones. 


\section{$>$ Ilustración 4. Estructura Organizacional}

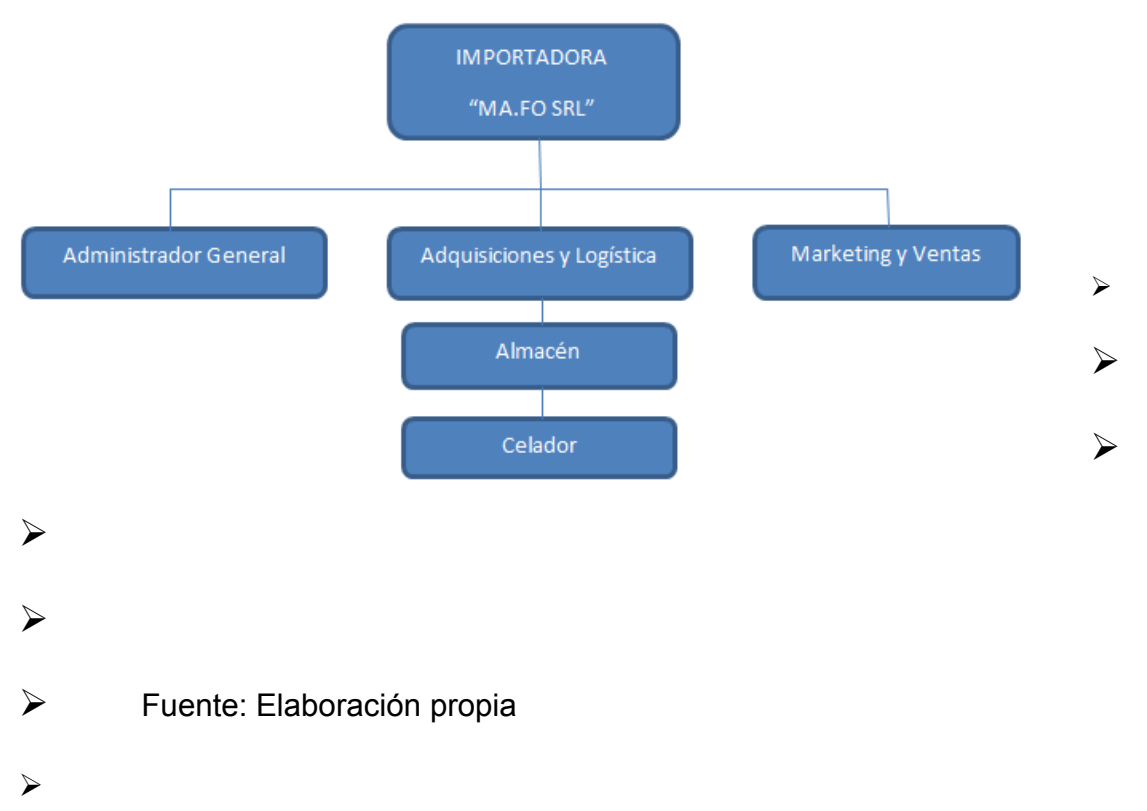

\section{- 2.1.4 Concepción financiera a largo plazo}

La estructura financiera que tendrá el emprendimiento objeto de estudio del presente documento, tendrá una base de capital propio y el faltante con préstamos de terceros.

$>\quad$ Se piensa que los préstamos recibidos sean a largo plazo, buscando un interés apropiado

\section{○ 2.2 Análisis político, económico, social y tecnológico (PEST)}

Toda planificación es difícil de proyectar debido a lo dinámico y complejo que son los sistemas políticos, económicos y sociales; existen varias herramientas eficaces que nos permitirán lidiar con posibles cambios que puede sufrir el entorno y así tomar decisiones idóneas para el cumplimiento de los objetivos propuestos.

D Esta herramienta nos ayudará a diseñar una estrategia para adaptarnos a las grandes tendencias que afectan al sector de la construcción en Bolivia, tocando aspectos políticos, económicos, sociales y tecnológicos.

\section{○ 2.2.1 Aspecto político - legal}

"Bolivia ha logrado mantener su estabilidad política tras la reforma impulsada por el presidente Evo Morales desde 2006"18 
$>\quad$ En lo que se refiere a seguridad jurídica el gobierno promulgó una ley de promoción a las inversiones ${ }^{19}$, la cual es específica en dar seguridad jurídica a inversiones con capital privado extranjeros como nacionales. En el art.21 $1^{20}$ de la nueva ley "el Estado podrá otorgar incentivos generales e incentivos específicos a todas las inversiones que se realicen en el país, en las condiciones establecidas en la presente ley". Los incentivos pueden ser desde aranceles, trasferencia de maquinaria, estabilidad tributaria, tarifas diferenciadas, entre otras.

\section{○ 2.2.2 Aspecto Económico}

La Comisión Económica para América Latina y el Caribe (CEPAL) ${ }^{21}$ indica que en lo que va del 2014 América Latina presenta un crecimiento económico moderado debido a la caída de los precios de las materias primas (petróleo, carbón, cobre, níquel), las cuales la región posee y exporta a países como china.

> Por otro lado, según el último informe de Microscopio Global 201422, "América Latina es líder en inclusión financiera, es decir ofrece más y mejores posibilidades para acceder a financiación y a sistemas para la gestión de recursos de ahorro y seguros, destacándose dos países Brasil y Bolivia”

> La calificadora internacional de riesgo Standard \& Poor's Ratings Servic (S\&P) ${ }^{23}$ señalo en mayo del 2014, que Bolivia además de presentar un crecimiento sostenido del Producto Interno Bruto (PIB) de $6,8 \%$ en 2013; de superávits fiscales y en la cuenta corriente han reducido la carga de la deuda, fortaleciendo la liquidez externa e incrementando la resistencia económica frente a shocks negativos; motivo por el que se elevó la calificación soberana de largo plazo en moneda local y extranjera a "BB" desde "BB-“ ; y confirmaron la calificación de corto plazo en "B".

19 Ley 1182. Ley de promoción inversiones recuperado(24 de noviembre 2014)

http://www.economiayfinanzas.gob.bo/index.php?

opcion=com_contenido\&ver $=$ contenido\&id=1023\&id_item $=265 \&$ seccion $=230 \&$ categoria $=327$

20 Ley 1182. Ley de promoción inversiones. Art №21 recuperado(24 de noviembre 2014)

http://www.economiayfinanzas.gob.bo/index.php?

opcion=com_contenido\&ver=contenido\&id=1023\&id_item $=265 \&$ seccion $=230 \&$ categoria $=327$

21 Comisión Económica para América Latina y el Caribe (CEPAL) recuperado (24 de noviembre 2014)

22Fondo multilateral de inversiones (FOMIN), miembro del grupo BID recuperado (25 de noviembre

2014)http://www.fomin.org/es-es/PORTADA/Noticias/Comunicados-de-prensa/ArticleID/2697/ArtMID/3819

23 Standard \& Poor's Ratings Servic (S\&P) recuperado (25 de noviembre 2014)

http://www.standardandpoors.com/ratings/articles/es/la/?articleType=HTML\&assetID=1245368451265 


\section{$>$ Ilustración 5. Escala de Clasificación de Riesgo de Standard \& Poor's}

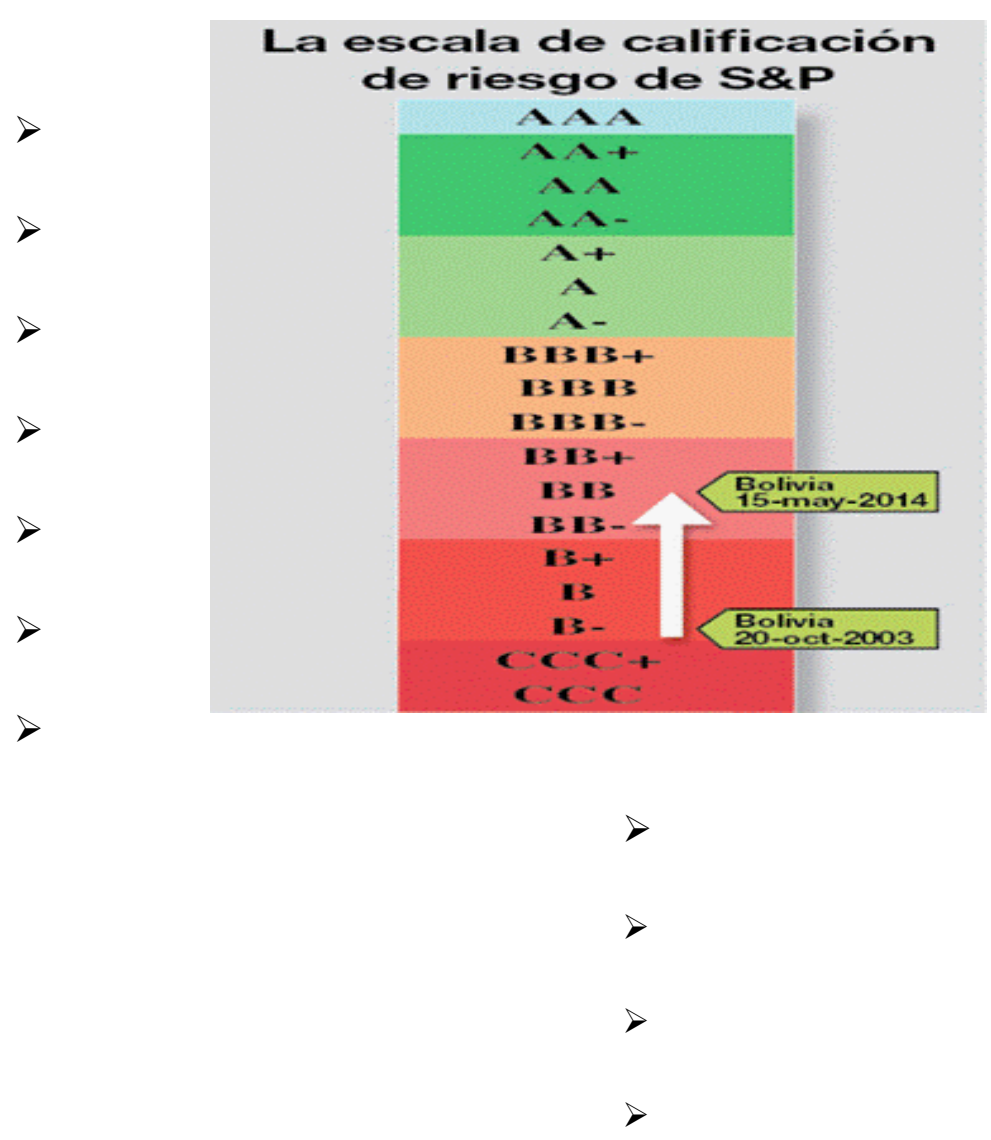

$>$ Fuente: Standard \& Poor's, Elaborado por el Ministerio de Economía y Finanzas de Bolivia.

\section{- 2.2.3 Aspecto Social}

Para los países latinoamericanos la reducción de la pobreza y erradicación del analfabetismo son uno de sus principales objetivos políticos.

$>\quad \mathrm{Si}$ bien en Bolivia mediante al buen contexto económico por el que está atravesando se dio lugar a la reducción de la pobreza moderada del $63 \%$ en 2002 al $45 \%$ en 2012 según datos del Instituto Nacional de Estadística (INE), la pobreza moderada afecta todavía al $45 \%{ }^{24}$ de la población y la desigualdad de ingresos sigue siendo elevada. Varios de los indicadores sociales aún están por debajo de los estándares de la región.

> Por otro lado, es importante mencionar que existe una gran cantidad de trabajadores bolivianos que radican fuera del país y con el envío de remesas aportan significativamente al sector económico; en el mes de junio del 2014 el Banco Central de 
Bolivia (BCB) ${ }^{25}$ registró $\$$ us 89,7 millones como consecuencia de las remesas recibidas; si bien se ve un ingreso notable de dinero al país el hecho de que tantos bolivianos en su mayoría pertenecientes al área rural hayan dejado Bolivia en busca de oportunidades laborales para tener un mejor estilo de vida, ha tenido también un impacto negativo en la sociedad, ya que produjo la desintegración de muchas familias.

\section{- 2.2.4 Aspecto tecnológico}

$>\quad$ Es una clara y concreta tendencia en el primer mundo y que está llegando a los países en desarrollo, la innovación aplicada a nuevos productos, priorizando el cuidado del medio ambiente, el uso de la energía, como también tiempo, costo y calidad.

> "En Bolivia, las constructoras de viviendas y edificios han comenzado a innovar en el empleo de materiales de última generación con el propósito de disminuir el empleo de la mano de obra, agilizar la ejecución de estructuras y evitar la utilización de materiales complementarios." ${ }^{26}$

\section{- 2.3 Análisis de las Fortalezas, Oportunidades, Debilidades y Amenazas (FODA)}

$>$ La presente herramienta nos ayudará a determinar las fortalezas y debilidades que mostrara nuestro proyecto al igual que las oportunidades y amenazas que tiene el entorno en el que se desarrollara; al cruzar las mismas tendremos las estrategias claves a utilizar.

\section{$>$ Oportunidades}

- Crecimiento del sector de la construcción en Bolivia

- Aumento en la demanda de la mano de obra, al igual que la importación de los insumos de construcción como el cemento y acero.

- Promulgación de nuevas leyes para la seguridad jurídica la inversión de capitales privados; como también para la financiación de nuevas construcciones.

- Incremento de los permisos de construcción en el eje troncal del país.

- Tendencias tecnológicas que se incrementan al momento de buscar productos e insumos que beneficien al sector de la construcción.

25 Banco Central de Bolivia recuperado( 25 de noviembre 2014) http://www.bcb.gob.bo/webdocs/2014/SalaDePrensa/NotasDePrensa/NP63.pdf

26 Quispe, Aline (Abril, 2014) Bolivia Emprende ,"La tecnología renueva la industria de la construcción en Bolivia", recuperado (26 de noviembre 2014) http://boliviaemprende.com/noticias/la-tecnologia-renueva-la-industria-de-la-construccion-en-bolivia 
- Las remesas que ingresan al país proveniente de bolivianos que trabajan en el exterior, mayormente son empleados para la construcción de viviendas propias.

- Bolivia tiene una buena relación bilateral con Argentina.

\section{Amenazas}

- El Ministerio de Relaciones Exteriores de Bolivia ${ }^{27}$ aseguró que la entrada de productos chinos a Bolivia se ha ido incrementando en los últimos meses en relación con años anteriores y si bien aún no existen membranas asfálticas de origen chino, la posibilidad de su ingreso es latente.

- Existen muchas marcas en el mercado de membranas asfálticas de origen argentino.

- Si bien Argentina es un país que tiene una amplia experiencia en la fabricación de insumos para la construcción y la exportación de los mismos, el control del manejo de las divisas por parte del gobierno trajo consigo muchos problemas al país, referido al comercio internacional.

\section{Fortalezas}

- Reconocimiento y buena imagen de los productos argentinos.

- Logística de distribución adecuada de las membranas asfálticas.

- La vida útil del producto ofertado es mucho mayor en comparación a los demás tipos de impermeabilizantes.

- El producto consta de certificación otorgada por el Instituto Argentino de Normalización y Certificación (IRAM)

\section{Debilidades}

- Empresa nueva en el mercado, con marcas nuevas

- Medidas de gobierno que no apoyen a la importación.

- En el mercado existen muchas marcas de industria argentina que se comercializan.

- Si bien Argentina es un país con mucha experiencia exportadora, el difícil acceso a las divisas, afecta a las negociaciones internacionales de compra y venta.

27 Ministerio de Relaciones Exteriores- Viceministerio de Comercio Exterior e Integración "Boletín Mensual Sobre Comercio Exterior De Bolivia" recuperado ( 30 de noviembre 2014) http://www.embajadadebolivia.es/pdf/Boletin\%20Mensual\%20de\%20Comercio\%20Exterior \%20de \%20Bolivia\%20a\%20febrero\%20de\%202014.pdf 
De la identificación de las variables tanto interna como externa se concluye que las debilidades y fortalezas estratégicas del sector de la construcción se relacionan principalmente con el aprovechamiento del crecimiento del mismo en Bolivia y de la buena percepción que tiene dicho mercado en cuanto a los productos de origen argentino.

Se debe aprovechar específicamente la industria desarrollada del sector de membranas asfálticas en Argentina, teniendo el acceso a una amplia red de proveedores del producto y con la posibilidad de distribuirlas en Bolivia.

\section{- 2.4 Análisis de las aspiraciones, restricciones y coordinación de las operaciones del proyecto (ARCO)}

$>$ Esta herramienta es un complemento al análisis FODA y no así un sustituto (París José, 2008, pp. 181-189). Con este método podremos apreciar cuales son las aspiraciones de los líderes, las restricciones ambientales, la capacidad de organización que se tendrá en el proyecto como también las oportunidades que se generan.

\section{- 2.4.1 Aspiraciones del proyecto}

- Se pensó en Bolivia debido a los datos proporcionados por diversas fuentes en los que se identifica un notable crecimiento del sector de la construcción.

- Nos orientamos por una economía primaria porque éstas no tienen mucha experiencia en temas de industria, por lo que necesitan de insumos para cubrir ciertas necesidades.

- Se trabajará mediante los beneficios que otorga el MERCOSUR.

- Se piensa en un proyecto de esta magnitud, para poder ser aplicado a cualquier otro tipo de producto ya que existen buenas relaciones comerciales entre Bolivia y Argentina.

\section{- 2.4.2 Restricciones del Proyecto}

\section{Restricciones ambientales}

$>\quad$ Existen muchos factores de los cuales debemos estar bien informados antes de realizar el proyecto en Bolivia, los cuales se detallan a continuación 
> Ilustración 6. Mapa Político de Bolivia

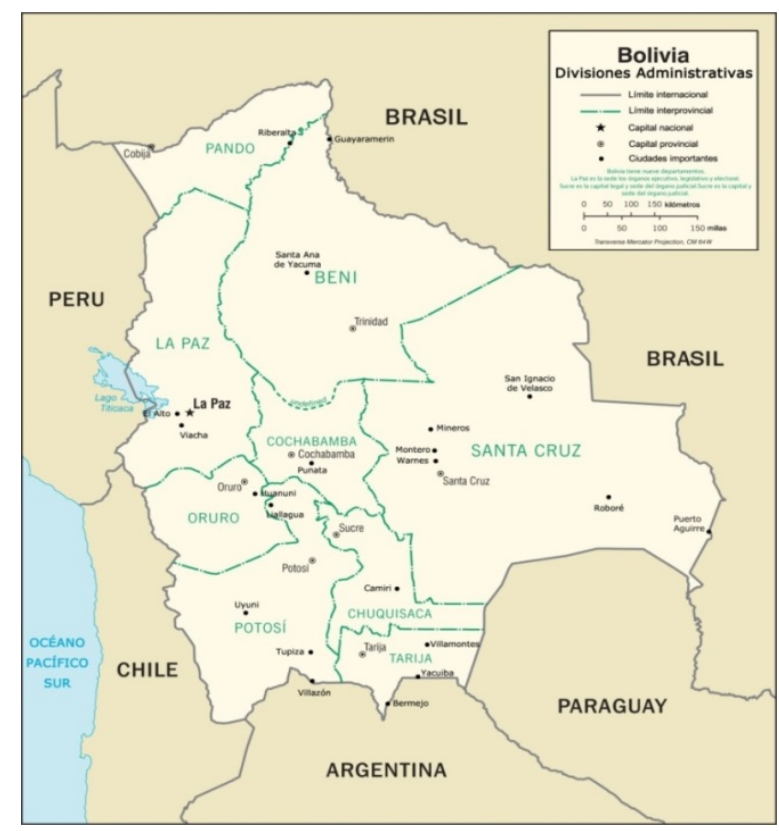

Tabla 7. Datos generales de Bolivia

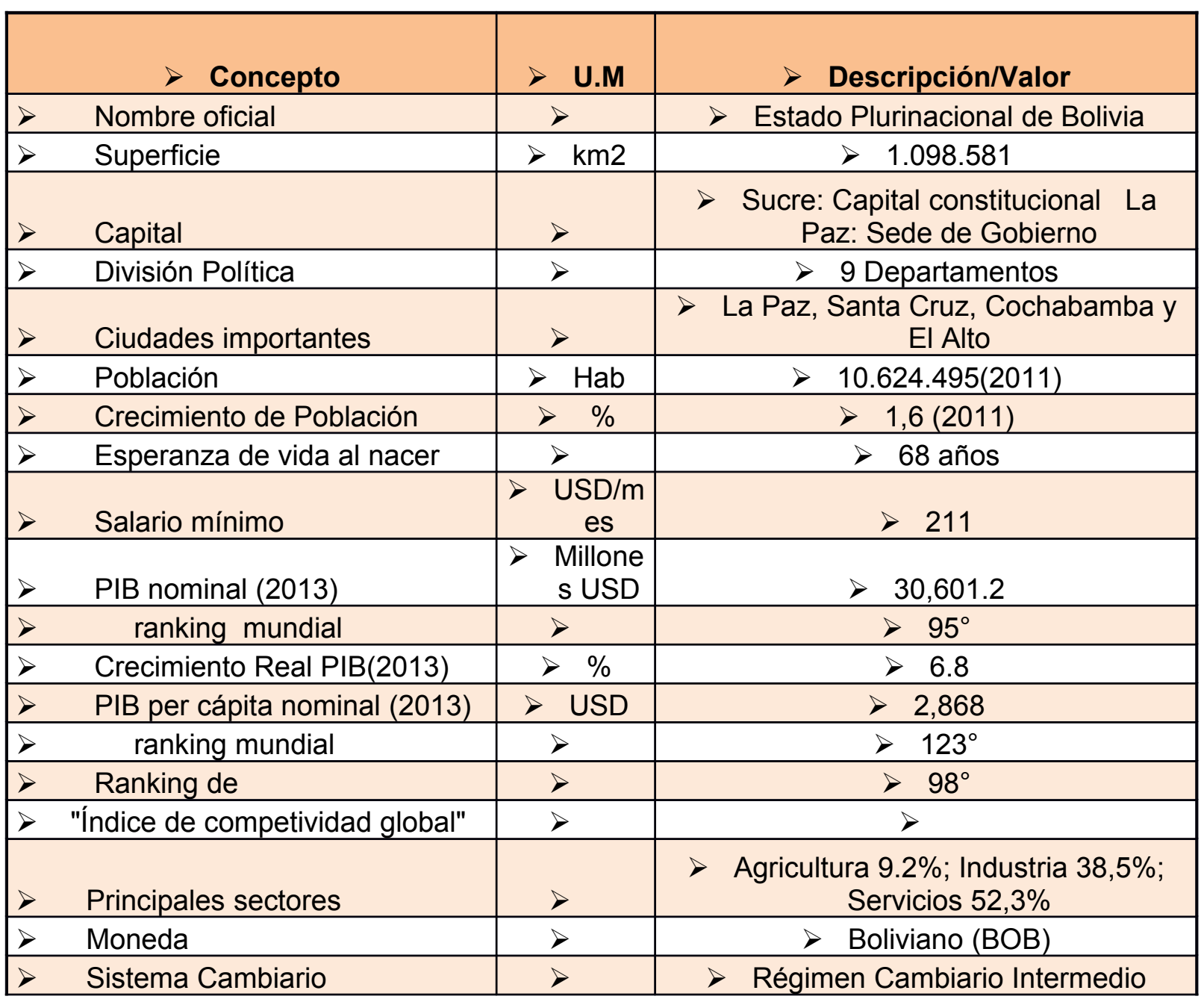




\begin{tabular}{|c|c|c|c|}
\hline$>$ & Desempleo & $>\quad \%$ & $>7,4$ \\
\hline 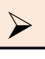 & Inflación & $>\%$ & $>6,5$ \\
\hline & Deuda externa total & $\begin{array}{r}\text { Millone } \\
\text { s USD }\end{array}$ & $>7,755.8$ \\
\hline & Exportaciones (2013) & $\begin{array}{r}\text { Millone } \\
\text { S USD } \\
\end{array}$ & $>10.436 .6$ \\
\hline & Principales Bienes & $>$ & $\begin{array}{l}\text { Gas natural; minerales de Zinc; tortas } \\
\text { y residuos sólidos de aceite de soya; } \\
\text { estaño; oro en bruto; minerales de } \\
\text { plomo; aceites crudos de petróleo. }\end{array}$ \\
\hline$>$ & Principales destinos & $>$ & $\begin{array}{c}\text { Brasil, Argentina, EEUU, Colombia, } \\
\text { Venezuela, Japón, República de } \\
\text { Corea, China, Canadá, Ecuador }\end{array}$ \\
\hline$>$ & & $>$ & $>$ \\
\hline & Importaciones (2013) & $\begin{array}{c}\text { Millone } \\
\text { s USD }\end{array}$ & $>7,494.1$ \\
\hline$>$ & Principales bienes & $>$ & $\begin{array}{l}\text { Aceites de petróleo; vehículos; } \\
\text { volquetes; barras de hierro; } \\
\text { electrógenos; preparaciones } \\
\text { alimenticias; teléfonos; tractores; } \\
\text { turbinas de gas. }\end{array}$ \\
\hline$>$ & Principales proveedores & $>$ & $\begin{array}{l}\text { Chile, Brasil, Argentina, EEUU, } \\
\text { China, Japón, México, España, } \\
\text { Alemania, Colombia, Italia, Suecia. }\end{array}$ \\
\hline
\end{tabular}

$>$ Tabla 8. Organizaciones internacionales de las cuales Bolivia es miembro

\begin{tabular}{|c|c|}
\hline$>\begin{array}{l}\mathbf{N} \\
0\end{array}$ & $>$ Nombre de la Organización \\
\hline$>1$ & $>$ Banco Interamericano de Desarrollo (BID) \\
\hline$>2$ & $>$ Banco Mundial (BM) \\
\hline$>3$ & $>$ Fondo Monetario Internacional (FMI) \\
\hline$>4$ & $>\quad$ Corporación Andina de Fomento (CAF) \\
\hline$>5$ & \begin{tabular}{|l|} 
Organización Mundial del Comercio \\
$(\mathrm{OMC})$
\end{tabular} \\
\hline$>6$ & $>$ Comunidad Andina de Naciones (CAN) \\
\hline$>7$ & $>\quad$ MERCOSUR (miembro asociado) \\
\hline$>8$ & $\begin{array}{l}\text { Asociación Latinoamericana de } \\
\text { Integración (ALADI). }\end{array}$ \\
\hline$>9$ & $\begin{array}{l}\text { Alternativa Bolivariana para las Américas } \\
\text { (ALBA). }\end{array}$ \\
\hline$>\begin{array}{r}1 \\
0\end{array}$ & $\begin{array}{ll} & \text { Foro de Países Exportadores de GAS } \\
\text { (FPEG) }\end{array}$ \\
\hline
\end{tabular}


Tabla 9. Acuerdos económicos y comerciales

\begin{tabular}{|c|c|c|}
\hline$>$ País o Grupo de Países & $\begin{array}{c}\text { Acuerd } \\
0\end{array}$ & Tipo de Acuerdo \\
\hline $\begin{array}{l}\text { Comunidad Andina } \\
\text { (Colombia, Ecuador y Perú) }\end{array}$ & $\begin{array}{l}>\begin{array}{l}\text { Subregio } \\
\text { nal }\end{array} \\
\end{array}$ & $>$ Acuerdo de Cartagena \\
\hline$>$ Chile & $>$ Bilateral & $\begin{array}{l}\text { Acuerdo complementación } \mathrm{N}^{\circ} \\
22\end{array}$ \\
\hline $\begin{array}{l}\text { MERCOSUR (Argentina, } \\
\text { Brasil, Paraguay y Uruguay) }\end{array}$ & $>$ Bilateral & $>$ Acuerdo complementación $N^{\circ} 36$ \\
\hline$>$ Cuba & $>$ Bilateral & $>$ Acuerdo complementación $\mathrm{N}^{\circ} 47$ \\
\hline$>$ México & $>$ Bilateral & $>$ Acuerdo complementación $N^{\circ} 66$ \\
\hline$>$ Venezuela & $>$ Bilateral & $>$ Acuerdo complementación \\
\hline$>$ Estados Unidos & $>\underset{1}{\text { Unilatera }}$ & $\begin{array}{l}\text { Sistema generalizado de } \\
\text { preferencia }\end{array}$ \\
\hline$>$ Japón & $>\underset{\mathrm{I}}{ }$ Unilatera & $\begin{array}{l}\text { Sistema generalizado de } \\
\text { preferencia }\end{array}$ \\
\hline$>$ Noruega & $>$ Unilatera & $\begin{array}{l}\text { Sistema generalizado de } \\
\text { preferencia }\end{array}$ \\
\hline$>$ Nueva Zelanda & $>\underset{\mathrm{I}}{ }$ Unilatera & $\begin{array}{l}\text { Sistema generalizado de } \\
\text { preferencia }\end{array}$ \\
\hline$>$ Rusia & \begin{tabular}{|l} 
Unilatera \\
1
\end{tabular} & $\begin{array}{l}\text { Sistema generalizado de } \\
\text { preferencia }\end{array}$ \\
\hline$>$ Suiza & $>\underset{\mathrm{I}}{\text { Unilatera }}$ & $\begin{array}{l}\text { Sistema generalizado de } \\
\text { preferencia }\end{array}$ \\
\hline$>$ Turquía & $\begin{array}{l}\text { Unilatera } \\
\mathrm{I}\end{array}$ & $\begin{array}{l}\text { Sistema generalizado de } \\
\text { preferencia }\end{array}$ \\
\hline$>$ Unión Europea & $>\underset{1}{\text { Unilatera }}$ & $\begin{array}{l}\text { Sistema generalizado de } \\
\text { preferencia }\end{array}$ \\
\hline$>$ Canadá & $>\underset{\mathrm{I}}{\mathrm{U}}$ Unilatera & $\begin{array}{l}\text { Sistema generalizado de } \\
\text { preferencia }\end{array}$ \\
\hline
\end{tabular}

Fuente: Instituto Boliviano de Comercio Exterior (IBCE) 


\section{Normas y reglamentos técnicos}

> "El Régimen de Importaciones establece prohibiciones de importación de bienes que afectan a la salud y vida humana, animal o contra la preservación vegetal, a la moral, al medio ambiente, la seguridad del Estado y el sistema financiero de la Nación y otras autorizaciones previas, expresadas en la Ley General de Aduanas, tales como sustancias controladas, (químicos, precursores y otros), dichas importaciones requieren autorización de la entidad encargada del control de tráfico de sustancias peligrosas." 28

$>$ En materia de normas técnicas, existen cuatro instituciones encargadas: el Consejo Nacional de Calidad, el Instituto Boliviano de Normalización y Calidad (IBNORCA), el Instituto Boliviano de Metrología (IBMETRO) y el Organismo Boliviano de Acreditación (OBA), son las responsables de la aprobación de normas técnicas, de la metrología y la acreditación.

\section{$>$ Restricciones Ecológicas}

> Hoy en día la preocupación por la preservación del medio ambiente es una problemática que afecta a todas las industrias y sectores.

> En lo referido a la construcción, a nivel mundial se ha ido implementando una nueva tendencia arquitectónica denominada "construcción sostenible", el concepto se basa en la construcción de azoteas o fachadas cubiertas de plantas; Bolivia no ha sido indiferente a tal iniciativa, por lo que la Federación de Empresarios Privados de Cochabamba (FEPC) ${ }^{29}$ bajo el lema "edificios verdes" quiso dar el ejemplo al sector, construyendo su sede con una fachada verde, es decir llena de plantas, en consecuencia y adoptando este concepto la alcaldía de la ciudad construyo un mercado con las mismas características.

Para poder lograr este tipo de construcciones es necesario utilizar distintos tipos de impermeabilizantes y/o aislantes térmicos.

\section{Restricciones Financieras}

$>$ En lo referido a financiación para la puesta en marcha del proyecto, en Bolivia recientemente el gobierno mediante el Decreto Supremo $(2055)^{30}$ fijo nuevas tasas de interés en créditos productivos, los cuales no pueden exceder el $6 \%$ anual para Pymes, el $7 \%$ para pequeñas y $11,5 \%$ para las microempresas. 


\section{Restricciones Culturales}

$>\quad$ En Bolivia uno de los impermeabilizantes que más se utiliza en los techos son las pinturas bituminosas, por su fácil aplicación y conveniente precio de venta.

\section{Restricciones Geográficas}

Si bien el país no cuenta con una salida marítima, lo cual no es un punto favorable en lo referido a comercialización internacional, cuentan con sistemas de comunicación e integración internacional con ventajas comparativas y competitivas que permiten una comunicación con sus principales ciudades como también con los países limítrofes, ya que geográficamente se ubica en el corazón de Sudamérica.

> El país tiene alrededor $70.000 \mathrm{~km}$ de carretera, de los cuales $10.000 \mathrm{~km}$ son pavimentados; también cuenta con la carretera Bioceánica que conecta al pacifico con el atlántico, uniendo los puertos de Santos, Brasil con Iquique, Chile; Asimismo existe; un ramal de la carretera Panamericana que cruza todo el altiplano que conecta a los países limítrofes. De igual manera presenta cuatro aeropuertos internacionales, Viru Viru ubicado en la ciudad de Santa Cruz, siendo el más importante, El Alto en la ciudad de La Paz y Jorge Wilsterman en Cochabamba y Cap. Oriel La Plaza en Tarija.

Si hablamos de vías fluviales existen $10.000 \mathrm{~km}$ comercialmente navegables, entre las que se destacan la Hidrovía Paraguay-Paraná en la cuenca del Plata, el eje Ichilo - Mamoré en la cuenca Amazónica y el comercio lacustre el Puerto Guaqui en la Cuenca Edorreica. Bolivia tiene convenios de navegación con Argentina, Brasil, Chile Paraguay y Perú, las cuales permiten el paso de barcazas con bandera boliviana por sus territorios para el transporte de comercial hacia los océanos Atlántico y Pacifico.

$>\quad$ Una vía de comunicación destacable es el sistema ferroviario dividido en dos redes importantes; la red oriental que conecta Argentina - Brasil y la red Occidental que conecta Argentina - Chile.

\section{- 2.4.3 Capacidades de la organización}

30 Decreto Supremo N²055 Fija las nuevas tasas de interés para créditos productivos, Ministerio de Economía y Finanzas del Estado Plurinacional de Bolivia recuperado (13 de diciembre 2014).

http://www.economiayfinanzas.gob.bo/index.php?

opcion $=$ com prensa\&ver $=$ prensa\&id $=3288 \&$ seccion $=306 \&$ categoria $=5$ 
$>$ Podemos destacar como una capacidad del negocio, a la red de proveedores de membranas asfálticas con las que se trabajará, todo esto con el afán de ofrecer productos que se acomoden a las necesidades de nuestros futuros clientes.

$>\quad$ Por otro lado el capital humano con el cual contará el emprendimiento será el más idóneo posible, profesionales del área que presenten habilidades, conocimientos y especialmente posean experiencia en todo lo referido a la comercialización, de igual manera se pretende que el equipo de trabajo tenga contactos en los canales comerciales.

\section{- 2.4.4 Oportunidades}

Habiendo realizado anteriormente un análisis del entorno y los riesgos a los cuales el emprendimiento se expondría, se presentan las siguientes oportunidades:

$>$ El producto es un insumo muy utilizado por el sector de la construcción como impermeabilizante.

$\checkmark \quad$ El mercado al cual se apunta creció en relación a años anteriores y todavía tiene una proyección de crecimiento.

Argentina es un país que presenta una fuerte marca como país en lo referido a la fabricación de productos de calidad.

Un factor de riesgo que alarma y si bien aún no se comercializan membranas asfálticas de origen chino en Bolivia, es algo que preocupa ya que de ser así se incrementaría la competencia.

\section{○ 2.5 Definición estratégica general del negocio}

La primera estrategia general de marketing internacional está enfocada en la identificación de una oportunidad comercial en otro país, en este caso Bolivia, luego determinamos cuales son las oportunidades, y amenazas que presenta el entorno al cual deseamos ingresar, como también las fortalezas y debilidades que nos podrían afectar como emprendimiento a futuro.

$>\quad$ El producto a importar son membranas asfálticas con geotextil transitable, debido a que actualmente las empresas constructoras bolivianas al momento de diseñar las 
infraestructuras buscan optimizar todos los espacios posibles; el techo es un área que puede ser utilizado como sector de lavandería, área de recreación o para un techo verde.

Si bien logran optimizar espacios el costo de incidencia en la obra es mayor debido a la tecnología e insumos requeridos, pero este tipo de obras brindan confort, una estética llamativa y logra ser atractiva para los futuros ocupantes.

$>$ Debido a lo mencionado anteriormente estamos interesados en vender la mercadería directamente a empresas constructoras, nuestro producto tiene calidad con un precio que irá acorde a dicha cualidad.

> Para generar una experiencia de compra diferenciada de nuestra competencia, brindaremos una breve capacitación acerca de cómo se debe aplicar el producto para una mejor duración del mismo, también entregaremos los instructivos necesarios, los cuales se muestran en el anexo 2. 


\section{Capítulo 3. Análisis del producto desde una perspectiva del marketing en}

Argentina

\subsection{Descripción del producto}

El producto que deseamos importar debe cumplir con las capacidades propuestas como empresa, que tenga buena calidad a un precio competitivo, para ello primero analizaremos las características intrínsecas e intangibles del mismo, posteriormente la amplia oferta de los proveedores argentinos.

\subsubsection{Atributos del producto intrínsecos, externos}

“Las membranas asfálticas están formadas por asfalto plástico, con armadura central de film de polietileno, al igual que la terminación inferior; y geotextil como refuerzo superior $^{\prime 31}$

llustración 7. Composición de las membranas asfálticas
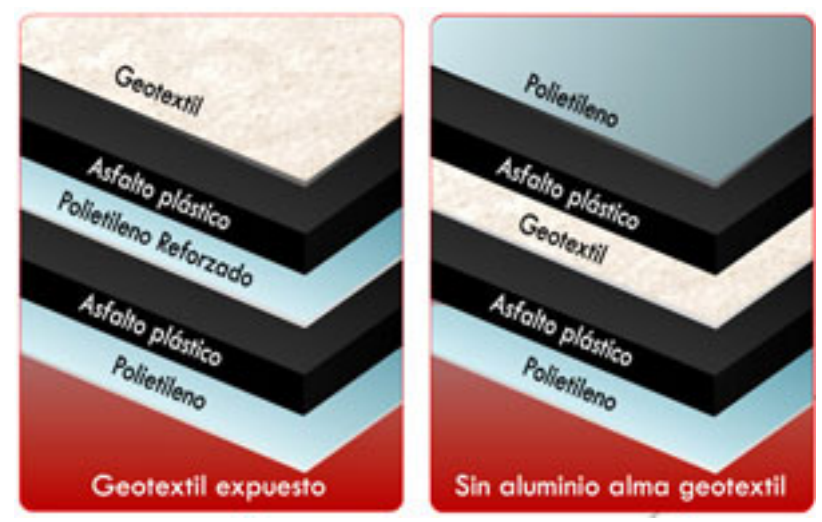


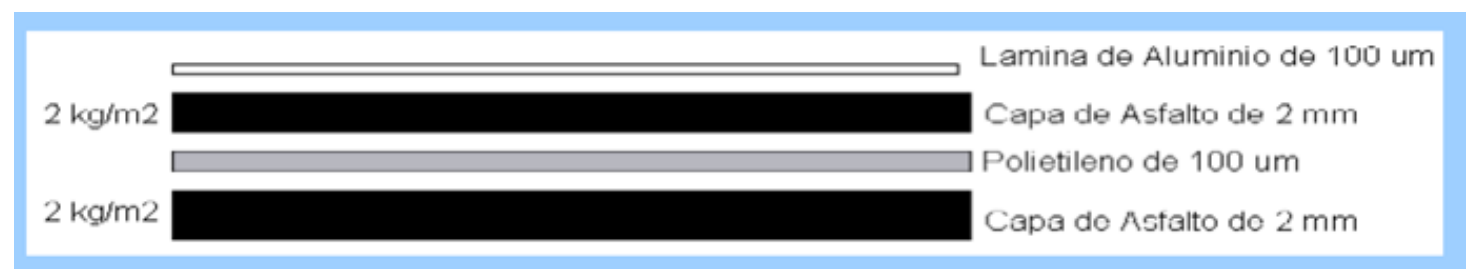

Fuente. Composición de las membranas Asfálticas- Fuente Instituto Nacional de Tecnología $(\mathrm{INTI})^{32}$

Dentro de las mayores ventajas que tiene este tipo de impermeabilizante en relación a los otros tenemos lo siguiente:

$\checkmark$ Es un producto pre elaborado, exclusivamente para impermeabilizar.

$\checkmark$ Maleable y de gran flexibilidad que se adapta a las distintas formas de superficies.

$\checkmark$ Prolongada vida útil por su composición.

$\checkmark$ Excelente elongación permite movimientos o asentamientos diferenciales sin perder sus propiedades hidráulicas.

$\checkmark$ Fácil y rápida instalación que reduce costos.

$\checkmark$ Mínima infraestructura de instalación.

$\checkmark$ Fácil transporte y manipuleo, rollos de $40 \mathrm{~kg}$ aproximado.

$\checkmark$ Resiste los cambios bruscos de temperatura.

$\checkmark$ Producto atóxico, no contamina los sólidos o líquidos que se encuentran en contacto con la membrana.

Por otro lado, en Argentina los productos que llevan el sello IRAM ${ }^{33}$, es porque el producto cumple con los requisitos necesarios en cuanto al control de la calidad en su fabricación (materias primas, proceso y producto terminado); en la tabla $\mathrm{N}^{\circ} 10$ se exponen los requisitos necesarios para la certificación de las membranas asfálticas con recubrimiento geotextil.

Estos datos los tomaremos como punto de referencia al momento de seleccionar a nuestros proveedores.

32 Instituto Internacional de Tecnología Industrial (INTI) recuperado( 30 de noviembre 2014) http://www.inti.gob.ar/iornadasgirsu2012/pdf/disertaciones/Panel InvestigacionDesarrolloTecnologiasRSU Membranas_Asfalticas_Alberto_Gauna.pdf 
Tabla 10. Requisitos Normas Nacionales Instituto Argentino de Normalización y Certificación (IRAM) 6693/6685.

\begin{tabular}{|c|c|}
\hline \multicolumn{2}{|c|}{$\begin{array}{l}\text { Requisito Normas Nacionales IRAM } 6693 \text { / } 6685 \\
\text { NBR } 9952 \text { Clase I de Internacionales }\end{array}$} \\
\hline ESPESOR & $\begin{array}{l}\text { Deberá ser uniforme y no podrá variar en más } \\
\text { o menos el } 10 \% \text { del valor indicado - IRAM } \\
1588\end{array}$ \\
\hline MASA POR M2 & Será de 3,2 kg/m2 mínimo - IRAM 1588 \\
\hline $\begin{array}{l}\text { MASA DE LAMINA } \\
\text { CENTRAL DE } \\
\text { POLIPROPILENO }\end{array}$ & $\begin{array}{l}\text { Será de } 0.050 \text { kg/m2 mínimo - AFNOR } 38012 \text { - } \\
\text { IRAM } 1581\end{array}$ \\
\hline $\begin{array}{l}\text { CARGA DE ROTURA } \\
\text { LONGITUDINAL }\end{array}$ & $\begin{array}{l}\text { Será de } 290 \text { n/CM mínimo - NBR } 9952 \text { - } \\
\text { CLASE I }\end{array}$ \\
\hline $\begin{array}{l}\text { CARGA DE ROTURA } \\
\text { TRANSVERSAL }\end{array}$ & Será de 290 n/cm mínimo - NBR 9952 - CLASE \\
\hline MASA BITUMINOSA & Será de 3.0 kg/m2 - mínimo - IRAM 1581 \\
\hline 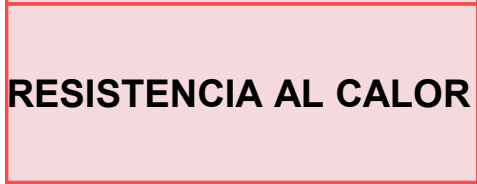 & $\begin{array}{l}\text { El aspecto general no presentará cambios } \\
\text { tales como flujo de masa bituminosa o } \\
\text { formación de ampollas. Alargamiento: } 2 \% \text { - } \\
\text { IRAM } 6685\end{array}$ \\
\hline PLEGABILIDAD & $\begin{array}{l}\text { Sobre un radio de } 12.5 \mathrm{~mm} \text {. a } 0^{\circ} \mathrm{C} \text {, realizado } \\
\text { en } 3 \mathrm{seg} \text {, sobre ambos lados no presentará } \\
\text { grietas, fisuras, desprendimientos de la masa } \\
\text { bituminosa, ni del material de carga - IRAM } \\
1595\end{array}$ \\
\hline PUNZONADA DINAMICO & $\begin{array}{l}\text { Será de } 2.45 \text { Joule mínimo - NBR } 9952 \text { - } \\
\text { CLASE I }\end{array}$ \\
\hline PUNZONADA ESTATICO & $\begin{array}{l}\text { Será de } 2.45 \mathrm{~N} / \mathrm{lh} \text { a } 23^{\circ} \mathrm{C} \text { mínimo - NBR } 9952 \text { - } \\
\text { CLASE I }\end{array}$ \\
\hline REFLECTIVIDAD & $\begin{array}{l}\text { Disminuye en un } 80 \% \text { el calor por irradación } \\
\text { solar }\end{array}$ \\
\hline
\end{tabular}


Fuente: Instituto Argentino de Normalización y Certificación (IRAM) ${ }^{34}$

\section{$\checkmark$ Empaque}

La presentación del producto es en rollos de $10 \mathrm{~m} 2$, en 1 metro de ancho $\times 10 \mathrm{mts}$ de largo, con un peso aproximado de $46 \mathrm{~kg}$, están empaquetados en bolsas las cuales tienen impresa la marca e industria.

Ilustración 8. Modelo de empaque de las membranas asfálticas.
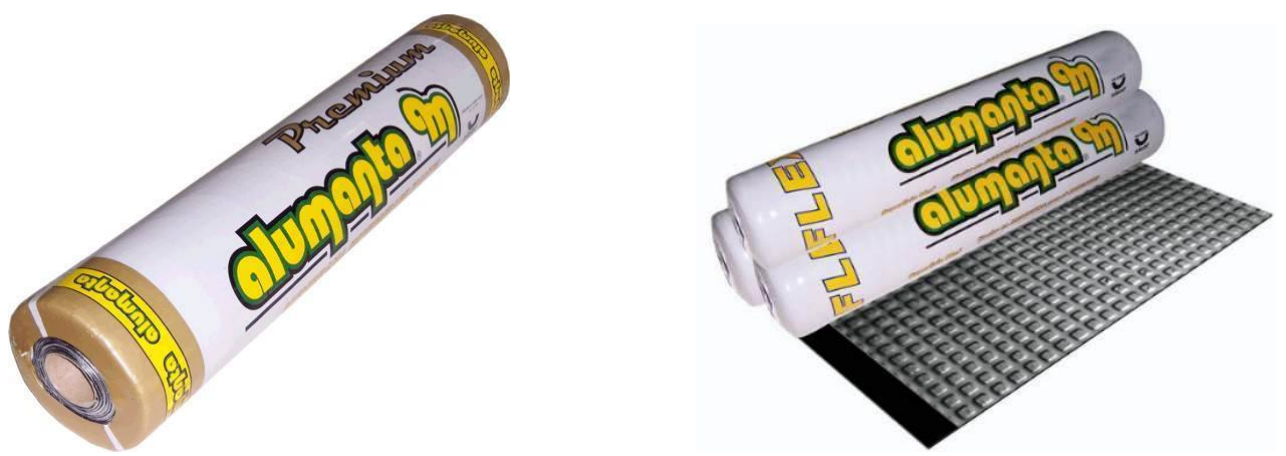

Fuente: Membranas Alumanec SRL ${ }^{35}$

\section{$\checkmark$ Embalaje}

Para una exportación el producto deberá estar encima de paletas, estas no pueden contener más de 25 unidades, para preservar el estado de la mercadería, tal como se refleja en la ilustración 9. 


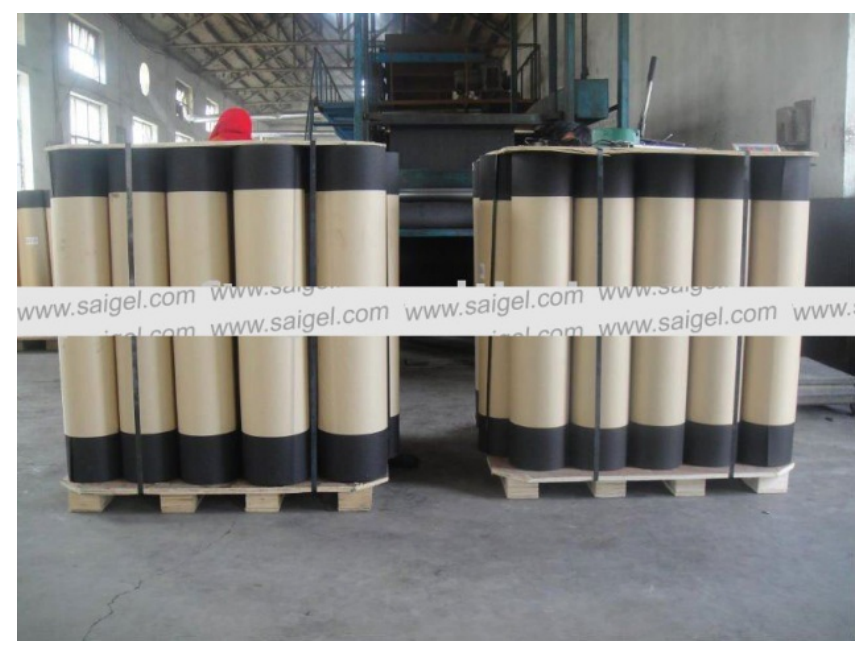

Ilustración 9. Embalaje adecuado para el transporte de la mercadería

\subsubsection{Atributos Intangibles}

Entre uno de los atributos intangibles que presenta nuestro producto, hace referencia a que Argentina tiene una excelente percepción como marca país en todo lo referido a fabricación de insumos de construcción, especialmente en Bolivia.

\subsection{Análisis de la oferta de las membranas asfálticas}

Las membranas asfálticas se iniciaron en el mercado argentino en $1979^{36}$, en la actualidad existen más de una decena de empresas dedicadas a la comercialización de este producto; pero solo cuatro son las que se distinguen por su capacidad exportadora; Megaflex, Sika Argentina, Emapi S.A y la compañía Breves S.A que trabajan bajo la marca de Ormiflex, estas empresas presentan una amplia gama de impermeabilizantes. En los siguientes gráficos podemos apreciar los distintos volúmenes de exportación en valor FOB que tuvieron en el transcurso de los últimos años.

Ilustración 10. Exportación Anual FOB USD “MEGAFLEX” (2009- 2004) 


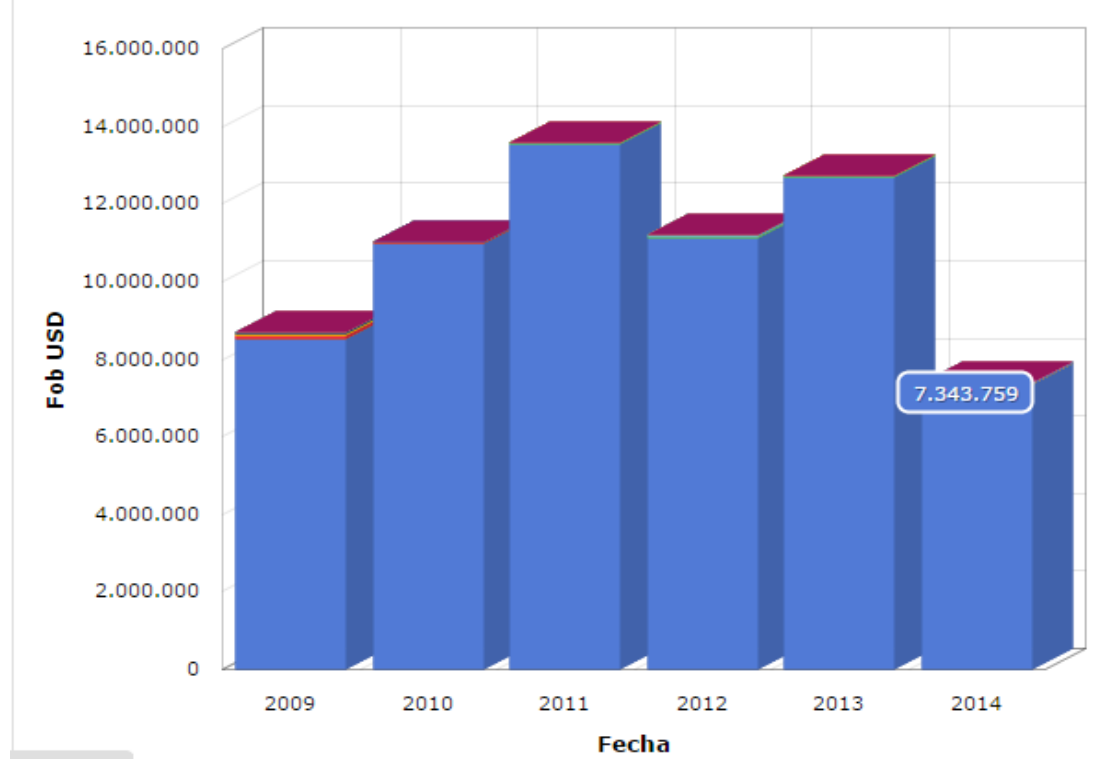

Fuente. Tradenosis ${ }^{37}$

llustración 11. Exportación Anual FOB UDS “EMAPI S.A” (2009-2014)

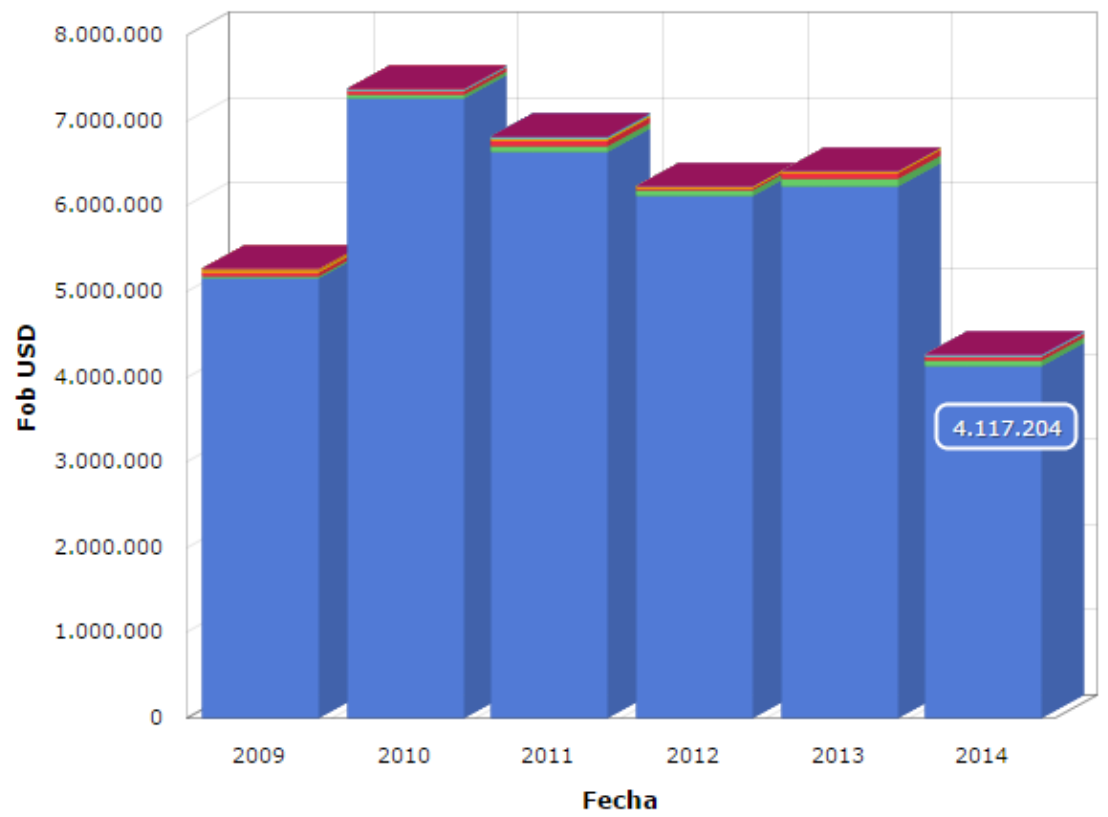

37 Servicio de búsqueda de negocios Tradenosis recuperado (02 de diciembre 2014) http://trade.nosis.com/es/MEGAFLEX-SA/30656825665/1/p?query=megaflex \%20sa\&utm source=TradeWeb\&utm Content=ResultBrowser\&utm campaign=Profiles\&utm medium=Tra deMedium\&pos=1\#.VPTLUfmG9LU 
Fuente. Tradenosis ${ }^{38}$

MEGAFLEX, EMAPI, SIKA, ORMIFLEX son marcas que tienen presencia en el mercado boliviano, razón por la cual estamos interesados en descubrir otras marcas de reconocimiento en el mercado doméstico, pero por uno $u$ otro motivo no tienen un departamento de comercio exterior, impidiendo exportar sus productos.

Las empresas con las características mencionadas anteriormente que fabrican membranas asfálticas con geotextil transitable en Argentina son LAMIPLAS, TECNITECH S.R.L, TECHFLEX S.A, MEMBRANAS ALUMANTEC SRL, bajo las marcas Lamiplas, Tecniphalt, Techflex y Alumanta Premium respectivamente, las demás no ofrecen el producto con las características que buscamos. ${ }^{39}$

\section{Ilustración 12. Marcas de posibles proveedores}
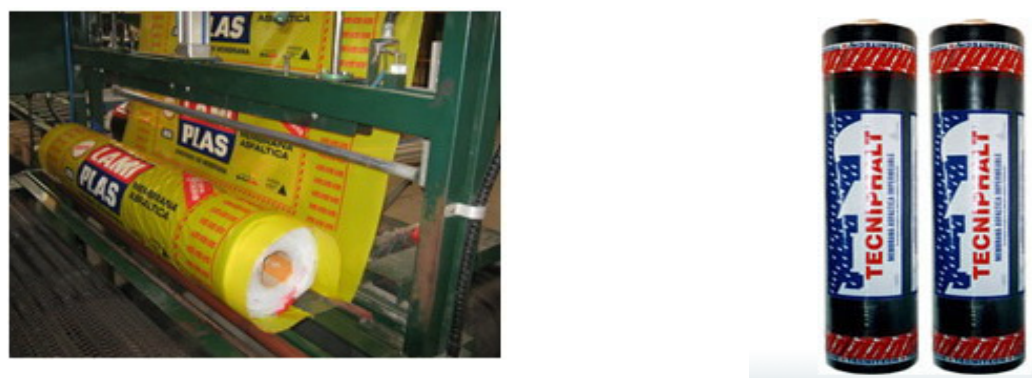

Fuente: www.lamiplas.com.ar

Fuente: www.tecnitech.com.arl

38 Servicio de búsqueda de negocios Tradenosis recuperado(02 de diciembre 2014) http://trade.nosis.com/es/EMAPISA/30503037226/1/p?query=emapi

\%20sa\&utm_source=TradeWeb\&utm_Content=ResultBrowser\&utm_campaign=Profiles\&utm_medium=TradeMedium\&pos= 1\#.VPTMCVMG9LU

39 Investigación de campo propia, realizada en Argentina; según lo obtenido de páginas web de las siguientes cámaras : Cámara de Comercio y Producción de Argentina http://www.cacipra.org.ar/ ; Cámara Argentina de Comercio (CAC) http://www.cac.com.ar/; Cámara Argentina de la Construcción (CAC) http://www.camarco.org.ar/ 


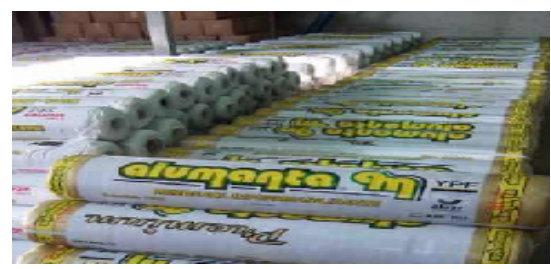

Fuente www.alumanta.com.ar

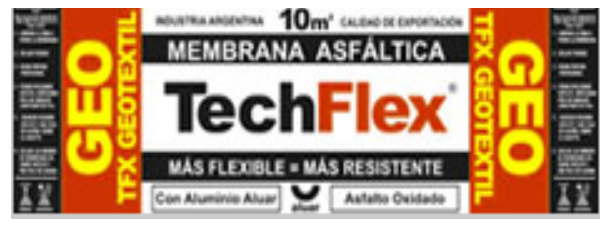

Fuente: www.techflex.com.ar

\subsection{Precio de Venta FOB}

En esta sección expondremos los precios con los que ofertan los posibles proveedores del producto a importar.

Tabla 11. Detalle de Precios de Proveedores

\begin{tabular}{|l|r|}
\hline \multicolumn{1}{|c|}{ Empresa } & \multicolumn{1}{c|}{$\begin{array}{c}\text { Precio FOB } \\
\text { U\$D }\end{array}$} \\
\hline Lamiplast & 52,5 \\
\hline Membranas Alumanec SRL & $\mathbf{4 1 , 2 1}$ \\
\hline Tecnitech S.R.L & 81,25 \\
\hline Techflex S.A & 58,41 \\
\hline
\end{tabular}

\section{Fuente: Elaboración Propia}

El mejor precio, es el ofertado por la empresa Membranas Alumanec SRL (ver anexo 3), debemos aclarar que la cotización fue bajo el incoterm EXW, mismo que será detallado en el siguiente punto.

\subsubsection{Incoterms (International Comercial Terms) ${ }^{40}$}

Los incoterms son un conjunto de reglas internacionales, regidos por la Cámara de Comercio Internacional (su última versión es la del 2010), las cuales determinan el alcance de las cláusulas comerciales incluidas en el contrato de compra y venta. 
En este caso puntual se determinó con el fabricante utilizar el Incoterm EXW (ex -works), es decir, el vendedor ha cumplido con su obligación de entrega del producto en su fábrica a disposición de la empresa importadora. El fabricante no es responsable ni de cargar la mercadería en el vehículo proporcionado por el comprador, ni de despacharla a la aduana para la exportación. La empresa importadora correrá con todos los gastos y riesgos de transportar la mercadería hasta Bolivia

\subsubsection{Medio y Forma de Pago}

El medio y forma de pago que elijamos va ligado al nivel de confianza que exista entre ambas partes es decir vendedor-comprador y antes de decidir es muy importante entender las principales diferencias entre ambos conceptos; la forma de pago son todos los acuerdos entre comprador y vendedor para determinar el momento del pago de la mercadería o servicio, éste va en relación al embarque y/o entrega del bien o servicio. En cambio, el medio de pago se refiere al tipo de transacción que se utilizará.

El pago de la mercadería será contra entrega y a la vista.

En el contrato de compra venta podemos fijar una cláusula que haga referencia a vicios ocultos, el mismo nos servirá de garantía negociar un plus de mercadería en forma de garantía (de un 2 a $5 \%$ ).

La intención es iniciar como una empresa importadora, para luego alcanzar la figura de Representante Comercial para el mercado boliviano de alguna de las marcas mencionadas.

Capítulo 4. Estrategia de marketing internacional para la importación de membranas asfálticas de origen argentino en el Estado Plurinacional de Bolivia

\subsection{Aspectos relevantes para la importación}


Para Czinkota y Ronkainen (2008) $)^{41}$ el comercio mundial ha creado una red de vínculos globales que unen a todos en general y por ende se incrementan las oportunidades de negocios internacionales, por lo cual todo tipo de empresa en cierta forma se ve obligada a involucrarse, ya sea de manera directa o indirecta debido al desarrollo económico y tecnológico.

El comercio internacional hace referencia al intercambio de bienes, productos y/o servicios comerciales entre distintos países, los cuales se encuentran regulados por la Organización Mundial del Comercio (OMC).

“La OMC dentro de sus funciones tiene administrar los acuerdos comerciales, servir de foro para las negociaciones comerciales, resolver las diferencias comerciales, supervisar las políticas comerciales nacionales, prestar asistencia a los países en desarrollo." ${ }^{42}$

\subsubsection{Posición arancelaria del producto}

Al tomar la determinación de exportar o importar un producto, es necesario asignarle una única posición arancelaria, con el objeto de obtener una interpretación legal uniforme que la define en término de denominación técnica y de referencia ${ }^{43}$

En la tabla 12 se detalla la clasificación de las membranas asfálticas con geotextil para superficies transitables.

Tabla 12. Posición Arancelaria de Productos a Importar

\begin{tabular}{|l|l|}
\hline \multicolumn{2}{|c|}{ Clasificación Arancelaria } \\
\hline Descripción (Sección XIII) & $\begin{array}{l}\text { Manufacturas de piedra, yeso fraguable, cemento, amianto } \\
\text { (asbesto), mica o materias análogas; productos cerámicos; } \\
\text { vidrios y manufacturas de vidrios }\end{array}$ \\
\hline Capítulo 68 & $\begin{array}{l}\text { Manufacturas de piedra, yeso fraguable, cemento, amianto } \\
\text { (asbesto), mica o materias análogas. }\end{array}$ \\
\hline Partida 68.07 & $\begin{array}{l}\text { Manufacturas de asfalto o de productos similares (por ejemplo: } \\
\text { Pez de petróleo, brea). }\end{array}$ \\
\hline $\begin{array}{l}\text { Sistema Amortizado } \\
6807.10 .00\end{array}$ & \\
\hline
\end{tabular}

Fuente: Aduana Nacional de Bolivia, Elaboración propia.

\section{Tabla 13. Aranceles aplicados al Producto}

41 Czinkota, Michael R. y Ronkainen, Ilkka A. (2008) “Marketing Internacional” (8va Ed) México Cengage Learning.

42 París, José Antonio “Marketing Internacional desde la óptica Latinoamericana” (1ra Ed) Buenos Aires: Errepar 2008. 
Aranceles Partida 6807.100.00

\begin{tabular}{|l|r|}
\hline Gravamen Arancelario Consolidado (G.A.C.) & $10 \%$ \\
\hline Impuesto al Valor Agregado (IVA) & $14,94 \%$ \\
\hline Gravamen Aduanero (G.A) & $15 \%$ \\
\hline Verificación & $1 \%$ del valor FOB \\
\hline $\begin{array}{l}\text { Cámara de industria comercio servicio y } \\
\text { turismo de Santa Cruz }\end{array}$ & $3 \%$ sobre el valor CIF \\
\hline
\end{tabular}

Fuente: Aduana Nacional de Bolivia.

\subsubsection{Documentos necesarios en origen}

Las marcas que deseamos comercializar de la empresa seleccionada no tienen presencia en el mercado boliviano debido a que no cuenta con un departamento de exportaciones. Por tal motivo las primeras exportaciones las realizaremos mediante un agente aduanero. Documentos básicos para presentar ante la Dirección General de Aduanas (DGA):

$\checkmark$ Declaración de Aduanas.

$\checkmark$ Documentos de Transporte.

$\checkmark$ Conocimiento de Embarque.

$\checkmark$ Factura Comercial definitiva.

$\checkmark$ Clasificación Arancelaria.

$\checkmark$ Documentos exigidos según lugar de origen (Certificado de Origen).

-Certificado de origen, en este caso emitido por el Instituto de Normalización Certificación (IRAM).

\subsection{Acuerdos comerciales entre el Estado Plurinacional de Bolivia y Argentina}

Argentina y Bolivia forman parte juntamente con otros países de la Asociación Latinoamericana de Integración (ALADI) y del Mercado Común del Sur (MERCOSUR).

En el acuerdo de complementación $\mathrm{N}^{\circ} 36^{44}$ firmado por Bolivia, Argentina, Paraguay, Brasil y Uruguay, el cual rige en Bolivia desde 1997, hace referencia al $100 \%$ de desgravación arancelaria de manera recíproca, constituyéndose una zona de libre comercio.

\subsection{Aspectos relevantes para la importación en destino}

\subsubsection{Documentos necesarios en destino ${ }^{45}$}

44 Aduana Nacional de Bolivia, recuperado (04 de diciembre del 2014),

http://www.aduana.gob.bo/aduana7/sites/default/files/kcfinder/files/origen/Normas\%20de\%200rigen.pdf 
$\checkmark$ Formulario interno de G.I.T, póliza flotante, 3 ejemplares.

$\checkmark$ Póliza de importación, 6 copias inclusive la original. 3. Aviso de Conformidad.

$\checkmark$ Factura Comercial.

Lista de Empaque.

$\checkmark$ Flete.

$\checkmark$ Seguro Flotante.

$\checkmark$ Factura de transporte (empresa transportadora).

$\checkmark$ Certificado Instituto Boliviano Normalización y Calidad.(IBNORCA)

$\checkmark$ Manifiesto de Carga.

$\checkmark$ Número Identificación Tributaria (NIT) de la empresa.

$\checkmark$ Parte de recepción.

$\checkmark$ Formulario 135

\section{Procedimientos en Aduana Nacional de Bolivia}

Entregar los documentos listados anteriormente, para proseguir con los siguientes pasos:

1. Ingreso de la mercadería al recinto aduanero para la elaboración del parte de recepción.

2. Presentación de la póliza de importación al recinto aduanero para la aceptación de los documentos.

3. Aforo documental y físico de las pólizas de importación por parte del vista de aduana.

4. Pago de tributos de importación en el banco autorizado.

5. Pago por servicios prestados por el recinto aduanero.

6. Extracción de la mercancía del recinto aduanero

\subsubsection{Barreras no arancelarias al ingreso del producto}

Las Barreras No Arancelarias, conocidas como regulaciones y requerimientos especiales para la importación de productos al mercado Boliviano, son esencialmente aplicados para la protección de la seguridad nacional y su economía, la conservación de la vegetación doméstica y la vida animal; así como para salvaguardar la salud de sus consumidores. 


\subsection{Determinación de la logística y transporte}

El envío de 23 toneladas de membranas asfálticas con terminación geotextil, para comercialización en Bolivia se realizará vía terrestre, el cual saldrá de la fábrica de nuestro proveedor ubicada en Merlo, Provincia de Buenos Aires hasta la aduana frontera Bermejo, será en un camión con capacidad para transportar un contenedor de 20"

Una vez nacionalizada la mercadería la misma empresa transportará la carga hasta nuestra bodega ubicada en Santa Cruz de la Sierra.

El tiempo de viaje de la mercadería desde Argentina a la frontera con Bolivia son de 15 días, se estima que el total del tiempo que tardará el producto en llegar hasta nuestra bodega será de 30 días, contabilizando el tiempo de traslado desde aduana Bermejo Tarija a la bodega de la empresa y el tiempo de la mercadería en depósito fiscal.

En la ilustración13 podemos observar los principales puntos estratégicos por lo que la mercadería transitará.

Inicialmente se pretende abastecer al mercado de la ciudad de Santa Cruz, con el objetivo de llegar a las ciudades de Cochabamba y La Paz; debemos destacar que nuestra importadora trabajará con consorcios de empresas constructoras, las cuales deberán retirar el producto de nuestro depósito.

Pero en el caso de las otras ciudades, se dará la opción de que las empresas corran por cuenta propia con el gasto del transporte o por el contrario para su comodidad, nosotros transportarla hasta el lugar que dispongan, claramente esto influirá en el precio de venta.

Ilustración 13. Itinerario Logístico 


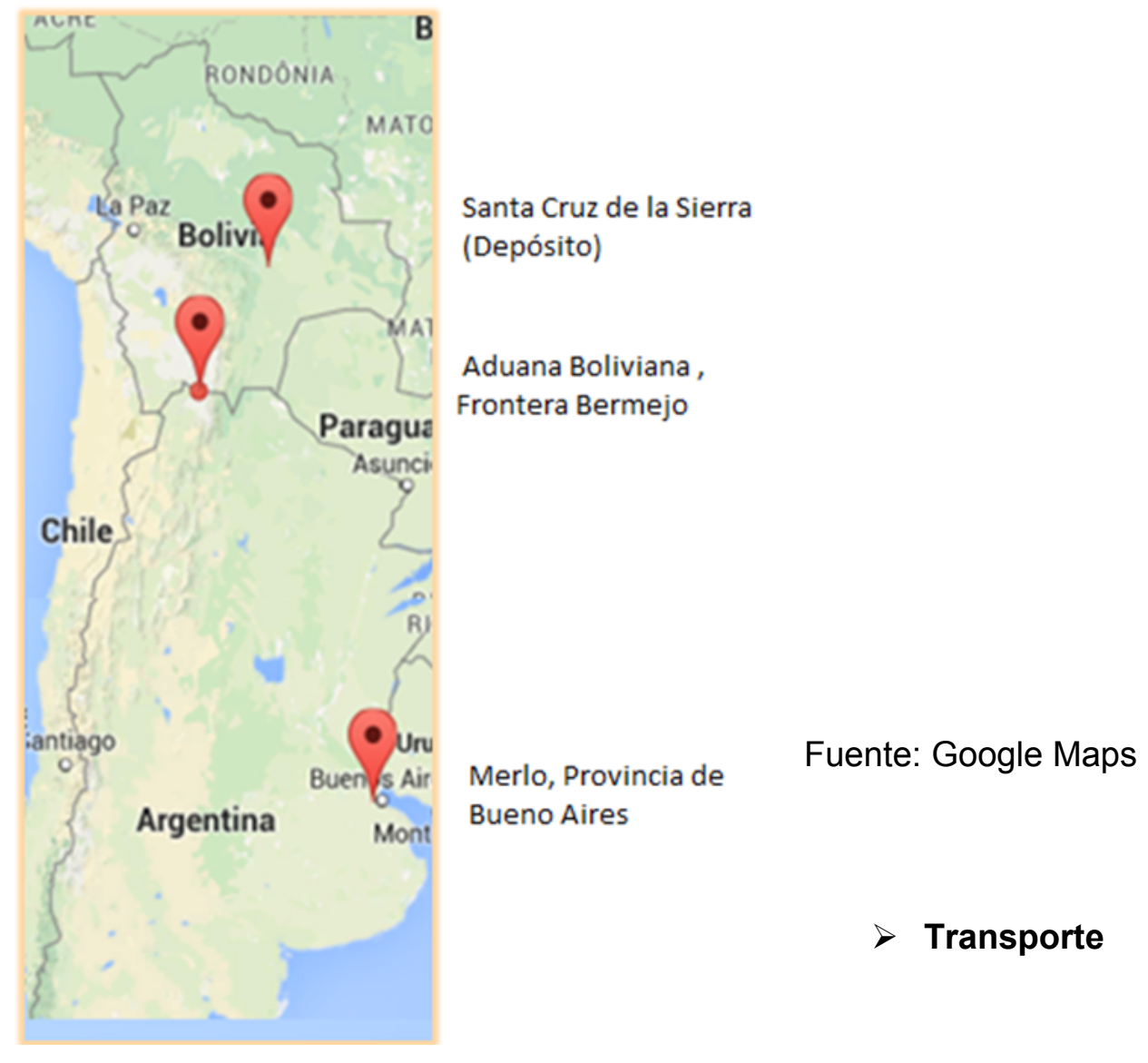

Como mencionamos anteriormente se decidió un transporte terrestre para la importación del producto, el camión que contrataremos tendrá capacidad para transportar un contenedor de 20 ".

Para determinar la elección del contenedor se tomó la información de la tabla N⒕

Tabla 14 . Información Necesaria para Determinar el Transporte

\begin{tabular}{|l|c|}
\hline \multicolumn{2}{|c|}{ Información Necesaria para Determinar el Transporte } \\
\hline \multicolumn{1}{|c|}{ Información Básica del Producto } \\
\hline Nombre Técnico & Manufacturas de asfalto en rollos \\
\hline Posición Arancelaria & 6807.10 .00 \\
\hline Unidad comercial de Venta & Rollo \\
\hline Valor unidad comercial & US41,21 \\
\hline Moneda & Dólares \\
\hline \multicolumn{2}{|c|}{ Argentina Básica de Despacho } \\
\hline País de origen & Merlo, Buenos Aires \\
\hline Ciudad punto de carga & Tarija \\
\hline País destino & Rollos de 1 x 10 mts \\
\hline Ciudad punto de descarga & 1,10 mts \\
\hline Tipo de empaque/embalaje & 25 \\
\hline Tipo de unidad de carga paletas & 24 \\
\hline \multicolumn{1}{|c|}{ Dimensiones } \\
\hline Nro. de unidades por paletas & 46 \\
\hline Volumen total del despacho $\mathrm{m}^{3}$ & 23 \\
\hline Peso por Rollo (Kg) & \\
\hline Peso total paletas (Tn) & \\
\hline
\end{tabular}


Fuente: Elaboración propia.

Con los datos anteriores determínanos que el peso total de la mercadería es de 23 tn y presenta un volumen de $24 \mathrm{~m}^{3}$. El contenedor más adecuado para el volumen y peso obtenido es el de 20 tn.

Ilustración 14. Modelo de contenedor 


\begin{tabular}{llr} 
STANDARD $20^{\circ}$ & Capacidad & $33.0 \mathrm{~m} 3$ \\
{$\left[20^{\circ} \times 8^{\prime} \times 8^{\prime}\right]$} & Volumen & $28,230 \mathrm{~kg}$ \\
& Peso máximo carga & $2,250 \mathrm{~kg}$ \\
& Tara & $30,480 \mathrm{~kg}$ \\
& Peso Bruto máximo & \\
\hline & Dimensiones internas & $5,900 \mathrm{~mm}$ \\
& Largo & $2,352 \mathrm{~mm}$ \\
& Ancho & $2,392 \mathrm{~mm}$ \\
& Alto & \\
& Apertura de techo & $2,340 \mathrm{~mm}$ \\
& Anchura & $2,280 \mathrm{~mm}$
\end{tabular}

Fuente: Aduana Nacional Argentina

El costo que involucra el transporte desde la fábrica a nuestro depósito asciende a USD 5.600 , el monto engloba la estiba de la mercadería, alquiler del contenedor y seguro de la mercadería.

Es importante recalcar que la transportadora se hará cargo de todo los trámites en frontera y destino en lo referido a la entrada y salida del contenedor. 


\section{Capítulo 5. Presupuesto y Control}

En el presente capítulo determinaremos el costo de importación del producto, especificaremos los ítems que engloban la inversión inicial del proyecto, para así poder determinar el precio de venta.

\subsection{Estructura del costo de importación}

El costo de importación engloba todos los gastos que se realizan en el proceso de importación del producto desde su compra, logística y transporte hasta nuestra bodega en Bolivia, todo esto para tener un posible precio de venta.

Tabla 15. Determinación del Precio CIF (Expresado en Dólares Americanos USD)

\begin{tabular}{|c|c|c|}
\hline \multicolumn{3}{|c|}{ DESGLOSE VALOR CIF Y BASE IMPONIBLE } \\
\hline CONCEPTO & & DOLARES \\
\hline Valor FOB & & $20.605,00$ \\
\hline Flete I (Origen - Frontera Argentina) & & $4.200,00$ \\
\hline $\begin{array}{l}\text { Flete II (Frontera Bermejo - } \\
\text { Depósito) }\end{array}$ & & $1.120,00$ \\
\hline Seguro & $2 \%$ & 110,00 \\
\hline Otros Gastos & & - \\
\hline CIF FRONTERA & & $24.915,00$ \\
\hline Otras Erogaciones & & 0 \\
\hline TOTAL GA & & 0 \\
\hline TOTAL IMPONIBLE & & $24.915,00$ \\
\hline
\end{tabular}

Fuente: Elaboración Propia

Tabla 16.

Determinación de los Tributos Aduaneros de Bolivia

(Expresado en Dólares USD)

\begin{tabular}{|c|c|}
\hline \multicolumn{2}{|c|}{ TRIBUTOS ADUANEROS } \\
\hline Gravamen Arancelario 15\% & - \\
\hline $\begin{array}{l}\text { Impuesto al Valor } \\
\text { Agregado (IVA) }^{46} \quad 14,94 \%\end{array}$ & $\begin{array}{l}3.72 \\
2,30\end{array}$ \\
\hline $\begin{array}{l}\text { Impuesto. Global } \\
\text { (uso sistema de la aduana) }\end{array}$ & 7,18 \\
\hline $\begin{array}{ll}\text { MULTAS } & 0 \%\end{array}$ & \\
\hline TOTAL & $\begin{array}{r}3 \\
729,48\end{array}$ \\
\hline
\end{tabular}

Fuente: Elaboración Propia

46 Impuesto al valor agregado Ley de Aduanas Bolivia, Decreto Supremo N 21530 "Reglamento al Valor Agregado" (recuperado 04 de diciembre 2014) file://C:/Users/Mayra\%20Fuentes/Downloads/Ley \%20843\%20Texto\%200rdenado\%20a\%20Diciembre\%202005.pdf 
En relación al cálculo de los tributos aduanero debemos mencionar que el porcentaje del gravamen arancelario para este producto es del $15 \%$, pero debido a que Bolivia y Argentina forman parte del Mercosur, no se aplicará; siempre y cuando el certificado de origen este correctamente llenado y dentro las fechas; vale decir posterior a la factura y anterior al embarque.

Tabla 17. Determinación de los Gastos por Despacho Aduanero (Expresado en Dólares)

\begin{tabular}{|l|r|}
\hline \multicolumn{2}{|c|}{ TOTAL GASTOS DE DESPACHO } \\
\hline COMISION & 201,15 \\
\hline ALMACENAJE & 0,00 \\
\hline CAM. COMERCIO & 0,00 \\
\hline CAM. AGENTES & 18,68 \\
\hline $\begin{array}{l}\text { IBNORCA (Instituto Boliviano de } \\
\text { Normalización y Calidad }\end{array}$ & 0,00 \\
\hline OTROS Gastos. & 0,00 \\
\hline TOTAL & $\mathbf{2 1 9 , 8 3}$ \\
\hline
\end{tabular}

Fuente: Elaboración propia.

La tabla 18 hace referencia al importe que se debe cancelar por la nacionalización de la mercadería.

Tabla 18. Detalle de Tributos y Despacho Aduanero a Pagar en Bolivia

\begin{tabular}{|l|r|}
\hline \multirow{2}{*}{ DETALLE } & \multicolumn{1}{c|}{$\begin{array}{c}\text { TOTAL TRIBUTOS Y } \\
\text { DESPACHO }\end{array}$} \\
\cline { 2 - 2 } & \multicolumn{1}{|c|}{ TOTAL DOLARES } \\
\hline TOTAL IMPUESTOS & $3.729,00$ \\
\hline TOTAL GASTOS & 331.00 \\
\hline TOTAL DESPACHO & $4.060,81$ \\
\hline
\end{tabular}

Fuente: Elaboración propia.

\subsection{Recursos e Inversiones}


Para poder dar paso a la realización de la primera importación, será necesario contar además de la mercadería con una serie de inversiones, las cuales se reflejan en la tabla 19.

Tabla 19.

Inversión Inicial

\begin{tabular}{|l|r|}
\hline \multicolumn{1}{|c|}{ Detalle } & \multicolumn{1}{c|}{ Monto } \\
\hline Deposito & $150.000,00$ \\
\hline Montacargas & $10.000,00$ \\
\hline Primera Importación & 20.605 \\
\hline Equipo de Computación & $1.600,00$ \\
\hline Sueldos y Salarios & $32.212,39$ \\
\hline Muebles y Enseres & $1.000,00$ \\
\hline Línea Telefónica & $1.000,00$ \\
\hline Gastos de Instalación & $2.000,00$ \\
\hline TOTAL & $\mathbf{2 1 8 . 4 1 7 , 3 9}$ \\
\hline
\end{tabular}

EL monto de la inversión inicial asciende a USD 218.417,39, de los cuales USD 202.817,39, representan nuestro capital de trabajo, por lo que necesitamos USD 15.600, para la puesta en marcha del proyecto. Por lo cual pediremos un préstamo bancario.

El préstamo lo realizaremos a un plazo de 3 años, con un interés del $10 \%$, a un plazo de 3 años, vale decir 36 meses con una cuota de interés mensual de USD 502,22. 


\begin{tabular}{|c|c|c|c|c|c|}
\hline Período & Mensualidad & Intereses & Amortización & Capital vivo & $\begin{array}{c}\text { Capital } \\
\text { Amortizado }\end{array}$ \\
\hline 0 & & & & $\$ 15.600,00$ & \\
\hline 1 & $\$ 502,22$ & $\$ 127,97$ & $\$ 374,26$ & $\$ 15.225,74$ & $\$ 374,26$ \\
\hline 2 & $\$ 502,22$ & $\$ 124,90$ & $\$ 377,33$ & $\$ 14.848,42$ & $\$ 751,58$ \\
\hline 3 & $\$ 502,22$ & $\$ 121,80$ & $\$ 380,42$ & $\$ 14.467,99$ & $\$ 1.132,01$ \\
\hline 4 & $\$ 502,22$ & $\$ 118,68$ & $\$ 383,54$ & $\$ 14.084,45$ & $\$ 1.515,55$ \\
\hline 5 & $\$ 502,22$ & $\$ 115,53$ & $\$ 386,69$ & $\$ 13.697,76$ & $\$ 1.902,24$ \\
\hline 6 & $\$ 502,22$ & $\$ 112,36$ & $\$ 389,86$ & $\$ 13.307,90$ & $\$ 2.292,10$ \\
\hline 7 & $\$ 502,22$ & $\$ 109,16$ & $\$ 393,06$ & $\$ 12.914,84$ & $\$ 2.685,16$ \\
\hline 8 & $\$ 502,22$ & $\$ 105,94$ & $\$ 396,28$ & $\$ 12.518,56$ & $\$ 3.081,44$ \\
\hline 9 & $\$ 502,22$ & $\$ 102,69$ & $\$ 399,53$ & $\$ 12.119,02$ & $\$ 3.480,98$ \\
\hline 10 & $\$ 502,22$ & $\$ 99,41$ & $\$ 402,81$ & $\$ 11.716,21$ & $\$ 3.883,79$ \\
\hline 11 & $\$ 502,22$ & $\$ 96,11$ & $\$ 406,12$ & $\$ 11.310,10$ & $\$ 4.289,90$ \\
\hline 12 & $\$ 502,22$ & $\$ 92,78$ & $\$ 409,45$ & $\$ 10.900,65$ & $\$ 4.699,35$ \\
\hline 13 & $\$ 502,22$ & $\$ 89,42$ & $\$ 412,81$ & $\$ 10.487,85$ & $\$ 5.112,15$ \\
\hline 14 & $\$ 502,22$ & $\$ 86,03$ & $\$ 416,19$ & $\$ 10.071,65$ & $\$ 5.528,35$ \\
\hline 15 & $\$ 502,22$ & $\$ 82,62$ & $\$ 419,61$ & $\$ 9.652,05$ & $\$ 5.947,95$ \\
\hline 16 & $\$ 502,22$ & $\$ 79,18$ & $\$ 423,05$ & $\$ 9.229,00$ & $\$ 6.371,00$ \\
\hline 17 & $\$ 502,22$ & $\$ 75,70$ & $\$ 426,52$ & $\$ 8.802,48$ & $\$ 6.797,52$ \\
\hline 18 & $\$ 502,22$ & $\$ 72,21$ & $\$ 430,02$ & $\$ 8.372,47$ & $\$ 7.227,53$ \\
\hline 19 & $\$ 502,22$ & $\$ 68,68$ & $\$ 433,54$ & $\$ 7.938,92$ & $\$ 7.661,08$ \\
\hline 20 & $\$ 502,22$ & $\$ 65,12$ & $\$ 437,10$ & $\$ 7.501,82$ & $\$ 8.098,18$ \\
\hline 21 & $\$ 502,22$ & $\$ 61,54$ & $\$ 440,69$ & $\$ 7.061,14$ & $\$ 8.538,86$ \\
\hline 22 & $\$ 502,22$ & $\$ 57,92$ & $\$ 444,30$ & $\$ 6.616,84$ & $\$ 8.983,16$ \\
\hline 23 & $\$ 502,22$ & $\$ 54,28$ & $\$ 447,95$ & $\$ 6.168,89$ & $\$ 9.431,11$ \\
\hline 24 & $\$ 502,22$ & $\$ 50,60$ & $\$ 451,62$ & $\$ 5.717,27$ & $\$ 9.882,73$ \\
\hline 25 & $\$ 502,22$ & $\$ 46,90$ & $\$ 455,32$ & $\$ 5.261,95$ & $\$ 10.338,05$ \\
\hline 26 & $\$ 502,22$ & $\$ 43,16$ & $\$ 459,06$ & $\$ 4.802,89$ & $\$ 10.797,11$ \\
\hline 27 & $\$ 502,22$ & $\$ 39,40$ & $\$ 462,83$ & $\$ 4.340,06$ & $\$ 11.259,94$ \\
\hline 28 & $\$ 502,22$ & $\$ 35,60$ & $\$ 466,62$ & $\$ 3.873,44$ & $\$ 11.726,56$ \\
\hline 29 & $\$ 502,22$ & $\$ 31,77$ & $\$ 470,45$ & $\$ 3.402,99$ & $\$ 12.197,01$ \\
\hline 30 & $\$ 502,22$ & $\$ 27,91$ & $\$ 474,31$ & $\$ 2.928,68$ & $\$ 12.671,32$ \\
\hline 31 & $\$ 502,22$ & $\$ 24,02$ & $\$ 478,20$ & $\$ 2.450,48$ & $\$ 13.149,52$ \\
\hline 32 & $\$ 502,22$ & $\$ 20,10$ & $\$ 482,12$ & $\$ 1.968,36$ & $\$ 13.631,64$ \\
\hline 33 & $\$ 502,22$ & $\$ 16,15$ & $\$ 486,08$ & $\$ 1.482,28$ & $\$ 14.117,72$ \\
\hline 34 & $\$ 502,22$ & $\$ 12,16$ & $\$ 490,06$ & $\$ 992,22$ & $\$ 14.607,78$ \\
\hline 35 & $\$ 502,22$ & $\$ 8,14$ & $\$ 494,08$ & $\$ 498,14$ & $\$ 15.101,86$ \\
\hline 36 & $\$ 502,22$ & $\$ 4,09$ & $\$ 498,14$ & $\$ 0,00$ & $\$ 15.600,00$ \\
\hline
\end{tabular}

Tabla 21.

Sueldo y Salarios del Personal (Expresado en Dólares)

\begin{tabular}{|l|r|r|r|r|}
\hline \multicolumn{1}{|c|}{ Cargo } & Sueldo & Cantidad & $\begin{array}{c}\text { Total } \\
\text { Mensual }\end{array}$ & $\begin{array}{c}\text { Total } \\
\text { Anual }\end{array}$ \\
\hline Administrador - Contable & 700,00 & 1 & $\begin{array}{c}700 \\
, 00\end{array}$ & $8.400,00$ \\
\hline Ventas & 400,00 & 2 & $\begin{array}{c}800 \\
, 00\end{array}$ & $9.600,00$ \\
\hline Compras y Logística & & 1 & 500 & \\
\hline
\end{tabular}




\begin{tabular}{|l|r|r|r|l|}
\hline & 500,00 & &, 00 & $6.000,00$ \\
\hline Depósito & 300,00 & 1 & $\begin{array}{c}300 \\
, 00\end{array}$ & $3.600,00$ \\
\hline Vigilancia y seguridad & 150,00 & 1 & $\begin{array}{c}150 \\
, 00\end{array}$ & $1.800,00$ \\
\hline TOTAL & $\mathbf{2 . 0 5 0 , 0 0}$ & $\mathbf{6}$ & $\mathbf{2 . 4 5 0 , 0 0}$ & $\mathbf{2 9 . 4 0 0 , 0 0}$ \\
\hline
\end{tabular}

Tabla 22.

Beneficios Sociales

(Expresado en Dólares)

\begin{tabular}{|l|r|r|r|}
\hline \multicolumn{1}{|c|}{ Cargo } & $\begin{array}{c}\text { Sueldo } \\
\text { (mensual) }\end{array}$ & $\begin{array}{c}\text { Aportes Afps - } \\
\text { CNS (14,94\%) }\end{array}$ & Total Anual \\
\hline Administrador & 700 & 100,94 & 800,94 \\
\hline Vendedor & 400 & 59,76 & 459,76 \\
\hline Vendedor & 400 & 59,76 & 459,76 \\
\hline Compra y Logística & 500 & 74,7 & 574,7 \\
\hline Depósito & 300 & 44,82 & 344,82 \\
\hline Vigilancia y Seguridad & 150 & 22,41 & 172,41 \\
\hline Total Beneficios & 2450 & 362,39 & 2812,39 \\
\hline
\end{tabular}


Tabla 23. Depreciación de Activos Fijos (Expresado en Dólares)

\begin{tabular}{|c|c|c|c|}
\hline Detalle & Valor & $\begin{array}{l}\text { Vida útil } \\
\text { (años) }\end{array}$ & $\begin{array}{c}\text { Depreciación } \\
\text { Anual }\end{array}$ \\
\hline Depósito & $150.000,00$ & 20 & $\begin{array}{r}7.50 \\
0,00 \\
\end{array}$ \\
\hline Montacargas & $5.000,00$ & 10 & 500 \\
\hline Computadoras & $1.600,00$ & 5 & 320 \\
\hline $\begin{array}{l}\text { Muebles y } \\
\text { Enseres }\end{array}$ & $1.000,00$ & 5 & 200 \\
\hline \multicolumn{3}{|c|}{ Total Depreciación Anual } & $\begin{array}{l}8.52 \\
0,00\end{array}$ \\
\hline \multicolumn{3}{|c|}{ Total Depreciación Mensual } & $\begin{array}{r}71 \\
0,00\end{array}$ \\
\hline
\end{tabular}

Tabla 24. $\quad$ Servicios Básicos (Expresado en Dólares)

\begin{tabular}{|l|r|}
\hline \multicolumn{1}{|c|}{ Detalle } & \multicolumn{1}{|c|}{$\begin{array}{l}\text { Importe } \\
\text { Mensual }\end{array}$} \\
\hline Agua & 50 \\
\hline E. Eléctrica & 60 \\
\hline Teléfono & 35 \\
\hline Total & $\mathbf{1 4 5}$ \\
\hline
\end{tabular}

\subsection{Determinación del precio de venta}

Según Arese, Félix (2003) $)^{47}$ para fijar el precio de una importación se deben tener en cuenta los gastos administrativos, todo lo relacionado a la obtención de certificados y documentos; descarga de terminales, transporte y seguros desde la fábrica hasta nuestro depósito; gastos aduaneros, tasas, impuestos; gastos bancarios, es decir las comisiones

47 Arese, Hector Felix(p 183) “Practica Profesional de Negocios Internacionales" 1ra Ed (2003) Grupo Editorial Norma 
y finalmente los gastos profesionales, honorarios de despachante de aduanas y transporte.

Una vez detallada las inversiones para la puesta en marcha del proyecto, podemos realizar el cálculo del precio de venta.

Tabla 25. Cálculo de Precio de Venta en Bolivia para la Primera Importación (Expresado en Dólares USD)

\begin{tabular}{|l|l|}
\hline \multicolumn{1}{|c|}{ DETALLE } & \multicolumn{1}{|c|}{ IMPORTE } \\
\hline Precio de Compra & $20.605,00$ \\
\hline Valor del Producto en Destino & $\mathbf{2 4 . 9 1 5 , 0 0}$ \\
\hline valor FOB & $20.605,00$ \\
\hline flete & $4.200,00$ \\
\hline Seguro & 110,00 \\
\hline Total a Pagar para Nacionalizar & $\mathbf{4 . 0 6 0 , 4 8}$ \\
\hline Gastos de despacho & 331,00 \\
\hline Impuestos & $3.729,48$ \\
\hline Gastos para el Ingreso a depósito & $\mathbf{2 . 7 6 3 , 0 0}$ \\
\hline Comisión Agencia Aduanera Argentina & 200,00 \\
\hline Certificación en Argentina & 150,00 \\
\hline Certificaciones en Bolivia & 100,00 \\
\hline Comisión bancaria & 193,00 \\
\hline Transporte Tarija- Deposito (Santa Cruz) & $1.120,00$ \\
\hline Comunicación y gastos logísticos & $1.000,00$ \\
\hline Gastos de Comercialización & $\mathbf{4 . 0 0 2 , 6 1}$ \\
\hline Sueldos y Salarios & $2.283,00$ \\
\hline Beneficios Sociales & 362,39 \\
\hline Intereses & 502,22 \\
\hline Depreciación & 710,00 \\
\hline Servicios (Luz, Agua, teléfono/ Internet) & 145,00 \\
\hline
\end{tabular}




\section{Costo del Producto en Deposito}

Utilidad del Importador (20\%)

Precio del Producto Importado

Precio de Venta por Unidad (Rollo)

Fuente: Elaboración propia.
$35.741,09$

$7.148,22$

$42.889,31$

85,78

Determinamos que el precio de venta para el mercado boliviano es de USD 85,78 por rollo de membrana asfáltica de origen argentino, con un margen de utilidad del $20 \%$. 


\section{Capítulo 6. Conclusiones Generales}

El análisis del proyecto fue realizado bajo los lineamientos del marketing internacional

El incremento en los índices de crecimiento en el sector de la construcción boliviana nos ha llevado a identificar oportunidades comerciales entre Argentina y Bolivia. Se decide estos dos países primeramente porque existe un mayor contacto con ambos mercados, por parte del maestrando; por otro lado en Bolivia la marca país de Argentina tiene una gran aceptación por la calidad en los productos que ofertan.

Se decidió importar membranas asfálticas con recubrimiento geotextil para superficies transitables para la impermeabilización de infraestructuras, debido a que se identificó que las empresas constructoras con el afán de optimizar espacios ven en los techos un área ideal, para la instalación del área de lavandería, como también para poder implementar la nueva tendencia arquitectónica de techos verdes.

Gracias a la concepción del marketing internacional pudimos identificar que en Bolivia se comercializan muchas marcas de membranas asfálticas con geotextil de origen argentino como lo son Megaflex, Emapi, Ormiflex, entre otras.

En Argentina existen muchas otras empresas que producen este tipo de impermeabilizantes y de muy buena calidad pero debido a que no tienen experiencia exportadora no pueden llegar a otros países, como es el caso de Bolivia.

Argentina y Bolivia forman parte del MERCOSUR, y gracias al acuerdo $\mathrm{N}^{\circ} 36$, este producto está libre de gravamen arancelario, siempre y cuando se cumplan todos los requisitos ya estipulados.

Para la primera experiencia importadora se planteó la compra de 500 rollos de membrana asfáltica los cuales se incrementarán en los subsiguientes pedidos, esto 
porque se tiene previsto que el sector de la construcción seguirá en crecimiento en 2015 y nosotros deseamos consolidarnos como representantes de la marca en Bolivia.

Se identificaron posibles proveedores del producto en Argentina, de los cuales la empresa Membranas Alumanec SRL con su marca Alumanta, es la que mejor precio de venta ofertó, debido a que están interesados en promocionar su marca en Bolivia.

El producto se pretende ofertar inicialmente a las empresas constructoras en Santa Cruz de la Sierra, ya que según los datos obtenidos es la ciudad que presento mayor crecimiento de empresas constructoras.

Para poder realizar la comercialización de la mercadería se creara una empresa con razón social MA.FO SRL, estará integrada por 6 personas distribuidas en el área administrativa, adquisición - logística, marketing - ventas y almacén.

El transporte será vía terrestre, el punto de origen es en la fábrica de nuestro proveedor ubicada en Merlo, provincia de Buenos Aires con destino en nuestro depósito ubicado en Santa Cruz de la Sierra, Bolivia.

Después de toda la clasificación de los gastos e inversiones incurridas en el proyecto se determinó que el precio de venta es de USD 85,78 por rollo de membrana, teniendo un margen de ganancia del $20 \%$.

Comparativamente con los precios de venta de mercado de rollos de membrana asfáltica con geotextil de industria Argentina con los precios ofertados en Bolivia, podemos decir que el producto a importar es competitivo en el mercado Boliviano 


\section{Anexos}

\section{Anexo 1}

"La Licenciada Ruiz, indico que el precio de venta de las membranas asfálticas con geotextil es de Bs.900 por rollo" (Ivon Ruiz, Encargada de ventas- Honnen Ltda, en comunicación personal 02 de marzo 2015).

La tabla adjunta hace referencia al precio de venta del producto en la ciudad de Santa Cruz de la Sierra, Bolivia.

\section{Proforma Empresa "HONNEN LTDA" 48}

\begin{tabular}{|c|l|c|c|c|}
\hline Cantidad & \multicolumn{1}{|c|}{ Detalle } & $\begin{array}{c}\text { Precio } \\
\text { Unitario } \\
\text { (Bolivianos) }\end{array}$ & $\begin{array}{c}\text { Tipo de } \\
\text { cambio }\end{array}$ & $\begin{array}{c}\text { Precio } \\
\text { Unitario } \\
\text { (Dólares) }\end{array}$ \\
\hline 1 & $\begin{array}{l}\text { Membranas Asfálticas con } \\
\text { geotextil rollo de 10 mts. } \\
\text { (Ormiflex) }\end{array}$ & 900 & 6,92 & 130,05 \\
\hline
\end{tabular}

Fuente: Elaboración en base a datos obtenidos vía telefónica

\section{Anexo 2}


Las instrucciones se obtuvieron de la página web www.emapi.com.ar y se transcriben de forma textual

\section{“Colocación de Membranas Asfálticas con Geotextil Transitable ${ }^{49}$}

\section{Paso $N^{\circ} 1$ Preparación de la superficie}

Se debe limpiar la superficie eliminando asperezas y/o elementos que puedan dañar la superficie de la membrana.

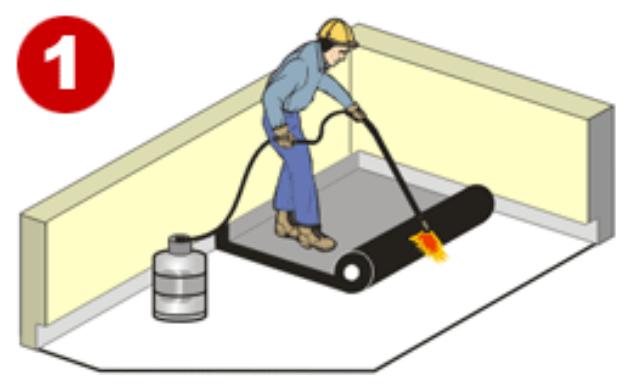

\section{Paso $N^{\circ} 2$ Imprimación}

Es recomendable adherir totalmente la membrana a la superficie, para ello aplicar dos manos de imprimación asfáltica.

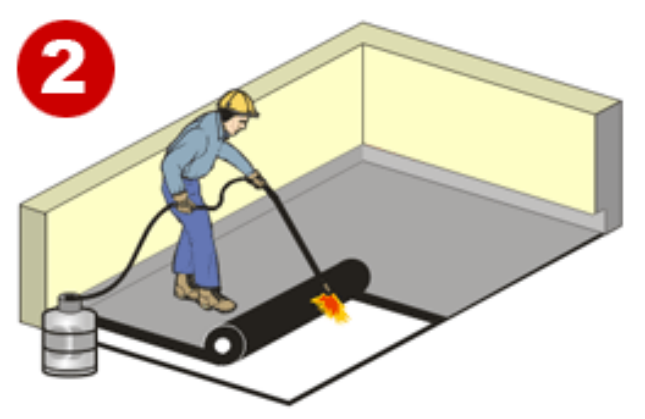

49Emapi SRL recuperado el 13 de diciembre del 2014 http://www.emapi.com.ar/Impermeabilizantes.aspx? idContenido $=152$ 


\section{Paso $N^{\circ} 3$ Colocación de la membrana}

Cuando la imprimación esté seca, calentar la parte inferior de la membrana al desenrollarla, fundiendo el polietileno para adherirla al sustrato; luego colocar los sucesivos rollos solapándolos entre sí 8 a $10 \mathrm{~cm}$.

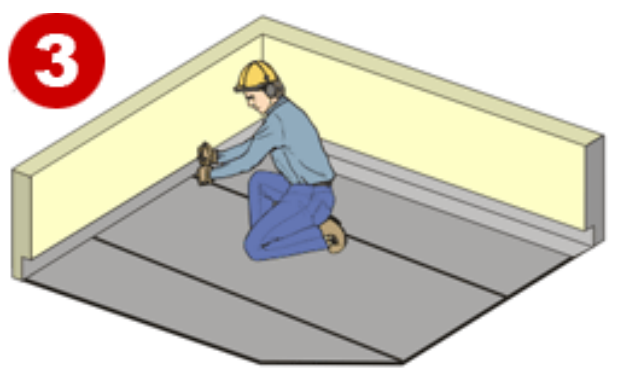

\section{Paso $N^{\circ} 4$ Terminación}

Cuando las membranas con geotextil expuesto van a ser protegidas mecánicamente con carpetas ceménticas u otros materiales pesados, se debe saturar el geotextil pintándolo con dos manos de imprimaciones asfálticas o con dos manos de emulsiones asfálticas y es recomendable, cuando la segunda mano de cualquiera de ellas esté aún fresca, efectuar un sembrado con arena para otorgarle una mayor resistencia mecánica y al desgaste.

Si las membranas con geotextil van a quedar expuestas a la intemperie $y$ al tránsito directo, el geotextil debe ser saturado con por lo menos dos 2 manos del revestimiento acrílico, a razón de 0,3 It/m por mano, en colores blanco (refleja más los rayos solares y beneficia el acondicionamiento térmico del techo y de la vivienda), terracota y verde." 


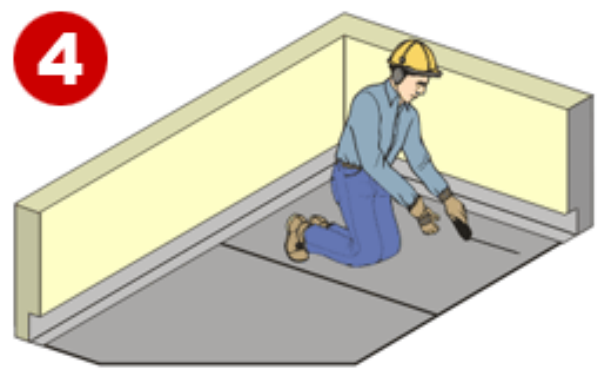

Anexo 3

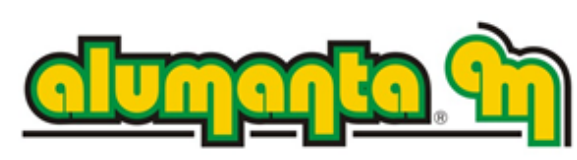

Membranas Asfálticas

Fabricación de Membranas y Pinturas Asfálticas

Señores: MAYRA

Tel. : $\quad \underline{1560307295}$

Atte.

De nuestra mayor consideración

Hacemos llegar nuestra mejor oferta por la provisión de los siguientes Productos:

\begin{tabular}{|c|c|c|c|}
\hline Item $\mid$ Cantidad & Descripción / Marca & & Precio Unitari \\
\hline & \multirow{2}{*}{\multicolumn{3}{|c|}{$\begin{array}{l}\text { Membrana GEOTEXTIL } \\
\text { ALUMANTA PREMIUM Con componente de Geotextil } 170 \text { Grs./M2 }\end{array}$}} \\
\hline & & & \\
\hline 10 & $\mathrm{~N}^{0} 0042$ GEO EXP & (Peso 46 Kgs) 3,40 mm & 329,75 + IVA \\
\hline 11 & $\mathrm{~N}^{0} 0050$ GEO EXP & (Peso $50 \mathrm{Kgs})$ 3,80/4,00 mm & 359,64 + IVA \\
\hline
\end{tabular}

Cotizacion: $001-$ MAYRA

COTIZACION ESPECIAL SEGÚN PEDIDO 



\section{Bibliografía}

Arese, Hector Felix (2003) Practica Profesional de Negocios Internacionales (1ra Ed) Buenos Aires, Grupo Editorial Norma

Czinkota, Michael R. y Ronkainen, Ilkka A. (2008) Marketing Internacional (8va Ed) México Cengage Learning.

Dimatre, Norberto (1998) La vivienda en tiempos remotos hasta nuestros días en el mediterráneo, Hábitat, Conservación \& Reciclaje, ed Buenos Aires

París, José Antonio (2008) Marketing Internacional desde la óptica Latinoamericana (1ra Ed) Buenos Aires Errepar.

París, José Antonio (2010) Negocios Internacionales desde Latinoamérica", (1ra Ed) Buenos Aires Errepar.

\section{Fuentes Secundarias}

Aduana Nacional de Bolivia

$<<$ http://www.aduana.gob.bo/aduana7/sites/default/files/kcfinder/files/origen/Norm as $\% 20$ de $\% 200$ rigen.pdf $>>$

Alumanec Srl.

<<http://www.alumanta.com.ar/empresa.php $>>$

American Chemical http

$<<: / / w w w . a m e r i c a n c h e m i c a l . c o m . b o />>$

Argentinaexporta

< http://www.argentinaexporta.com/nomeclatura.html >>

Asociación Latinoamericana de Integración (ALADI)

$<<$ http://consultawebv2.aladi.org/sicoexV2/jsf/comercio_exterior_principales_socio

s resultado.seam?cid $=1080>>$

Banco Mundial

<<http://www.bancomundial.org/es/country/bolivia/overview\#1 >>

Banco Central de Bolivia recuperado de <<http://www.bcb.gob.bo/webdocs/2014/SalaDePrensa/NotasDePrensa/NP63.pdf $>$ 
Boletín Mensual sobre Comercio Exterior de Bolivia $<$ <http://www.embajadadebolivia.es $>>$

Cámara Nacional de la Construcción de Bolivia $<<$ http://www.caboco.org.bo/>>

Cámara de Comercio y Producción de Argentina $<$ http://www.cacipra.org.ar $>>$

Cámara Argentina de Comercio $<<$ http://www.cac.com.ar $>>$

Cámara de la construcción de Santa Cruz (CADECRUZ) $<<$ http://www.cadecocruz.org.bo/construir/construir10/index.html >>

Cámara de la Construcción Cochabamba (CADECO)

$<<$ http://www.cadecocbba.com/controladores/index.php >>

Cámara de la Construcción de La Paz (CADECO - LA PAZ) $<<$ http://www.cadecolp.com/>>

Comisión Económica para América Latina y El Caribe (CEPAL)

<<http://www.cepal.org/publicaciones/xml/6/51946/AnuarioEstadistico2013.pdf>>

Decreto Supremo N²055,

$<<$ http://www.economiayfinanzas.gob.bo/index.php?

opcion $=$ com_prensa\&ver $=$ prensa\&id $=3288 \&$ seccion $=306 \&$ categoria $=5>>$

Decreto Supremo $N^{\circ} 2055$, Ministerio de Economía y Finanzas del Estado Plurinacional de Bolivia

<<http://www.economiayfinanzas.gob.bo/index.php? opcion=com_prensa\&ver=prensa\&id=3288\&seccion=306\&categoria=5 >>

El Banco Mundial, $\quad$ Panorama General <<http://www.bancomundial.org/es/country/bolivia/overview\#1>>

Emapi SRL <<http://www.emapi.com.ar/lmpermeabilizantes.aspx?idContenido=152>>

Enkimembrana <http://enkimembrana.com/membrana-transitable/>> 
Fondo Monetario

de

Inversión

<<http://www.imf.org/external/spanish/np/tr/2014/tr021014s.htm>>

Fundación ExportAr

<<http://www.exportar.org.ar/web2013/accion.php?st=fer\&ndoc=999>>

Fondo multilateral de inversiones (FOMIN), miembro del grupo BID <<http://www.fomin.org/es-es/PORTADA/Noticias/Comunicados-deprensa/ArticleID/2697/ArtMID/3819>>

Federación de Empresarios Privados de Cochabamba (FEPC) <<http://www.fepc.org.bo/index.php/es/biblioteca-virtual/revistas $>>$

Gaceta Oficial del Estado Plurinacional de Bolivia <<http://www.gacetaoficialdebolivia.gob.bo/>>

Instituto de Tecnología Industrial (INTI) "Reciclado de Membranas Asfálticas" de

<<http://www.inti.gob.ar/jornadasgirsu2012/pdf/disertaciones/Panel_Investigacion DesarrolloTecnologiasRSU/Membranas Asfalticas_Alberto_Gauna.pdf >>

Honnen Ltda. $<<$ http://www.honnen.com.bo/subopcion.php?

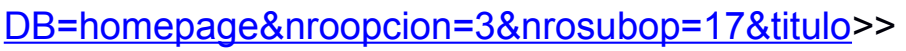

Instituto Nacional de Estadística de Bolivia

$(\mathrm{INE})$ $<<$ http://www.ine.gob.bo/indice/general.aspx?codigo=40221>>

Instituto Boliviano de Comercio Exterior (IBCE)

$<<$ http://ibce.org.bo/haga-negocios-informacion-paraimportar.php\#.VHc3VluG9LU>>

Instituto Argentino de Normalización y Certificación (IRAM)

<<http://www.inti.gob.ar/jornadasgirsu2012/pdf/disertaciones/Panel_Investigacion DesarrolloTecnologiasRSU/Membranas_Asfalticas_Alberto_Gauna.pdf >>

Isomat Srl.

<<http://www.bo.all.biz/isomat-srl-e2991\#.VPSlevmG9LU>>

Ley 1182. Ley de promoción inversiones. Art $\mathrm{N}^{\circ} 21$ $<<$ http://www.economiayfinanzas.gob.bo/index.php?

opcion=com_contenido\&ver $=$ contenido $\&$ id $=1023 \&$ id_item $=265 \&$ seccion $=230 \&$ cate goria $=327>>$ 
Ley N³93" Ley de Servicios Financieros

<<https://www.bcb.gob.bo/webdocs/sipav/Leyes/Ley393.pdf >>

Membranas Avellaneda,

$<$ <http://www.membranasavellaneda.com.ar/>>

Ministerio de Relaciones Exteriores - Viceministerio de Comercio Exterior e Integración

$<<$ http://www.economiayfinanzas.gob.bo/index.php?

opcion=com_contenido\&ver=contenido\&id=1023\&id_item $=265 \&$ seccion $=230 \&$ categoria $=3$ $\underline{27}>>$

Pinturas Monopol Sa

$<$ http://www.pinturasmonopol.com/ >>

Servicio de búsqueda de negocios Tradenosis

<<http://trade.nosis.com/es/EMAPI-SA/30503037226/1/p?query=emapi

\%20sa\&utm_source=TradeWeb\&utm_Content=ResultBrowser\&utm_campaign=Pr ofiles\&utm_medium=TradeMedium\&pos=1\#.VPTMCVmG9LU>>

Sika Bolivia S.A

< http://bol.sika.com/es/solutions_products.html >>

Standard \& Poor's Ratings Servic

$<<$ http://www.standardandpoors.com/ratings/articles/es/la/? articleType $=$ HTML\&asset|D $=1245368451265>>$

Quispe, Aline (Abril, 2014) Bolivia Emprende, "La tecnología renueva la industria de la construcción en Bolivia",

$<<$ http://boliviaemprende.com/noticias/la-tecnologia-renueva-la-industria-de-laconstruccion-en-bolivia>> 

Declaro bajó juramento que esta tesis fue elaborada por mí, que no utilice ningún otro material que no haya dado a conocer en las referencias y que no utilicé frases o párrafos de otro autores y que este trabajo de tesis nunca ha sido presentado ante un comité de evaluación de tesis y que no transgrede derechos de terceros. 